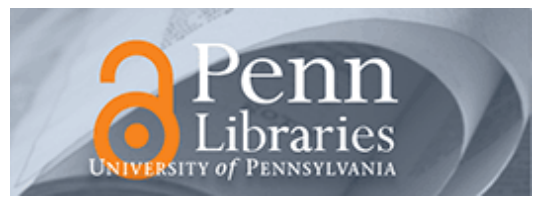

University of Pennsylvania ScholarlyCommons

Marketing Papers

Wharton Faculty Research

$9-2008$

\title{
A Price Discrimination Model of Trade Promotions
}

Tony Haitao Cui

University of Pennsylvania

Jagmohan S. Raju

University of Pennsylvania

Z John Zhang

University of Pennsylvania

Follow this and additional works at: https://repository.upenn.edu/marketing_papers

Part of the Marketing Commons

\section{Recommended Citation}

Cui, T., Raju, J. S., \& Zhang, Z. (2008). A Price Discrimination Model of Trade Promotions. Marketing Science, 27 (5), 779-795. http://dx.doi.org/10.1287/mksc.1070.0314

This paper is posted at ScholarlyCommons. https://repository.upenn.edu/marketing_papers/199

For more information, please contact repository@pobox.upenn.edu. 


\title{
A Price Discrimination Model of Trade Promotions
}

\begin{abstract}
Critics have long faulted the wide-spread practice of trade promotions as wasteful. It has been estimated that this practice adds up to $\$ 100$ billion worth of inventory to the distribution system. Yet, the practice continues. In this paper, we propose a price discrimination model of trade promotions. We show that in a distribution channel characterized by a dominant retailer, a manufacturer has incentives to price discriminate between the dominant retailer and smaller independents. While offering all retailers the same pricing policy, price discrimination can be implemented through trade promotions because they induce different inventory-ordering behaviors on the part of retailers.

Differences in inventory holding costs have been shown to be an important determinant of consumer promotions. Our analysis suggests that differences in holding costs are also potentially an important driver for the use of trade promotions. The implications from our model explain a number of anecdotal and/or empirically observed puzzles about how trade promotions are practiced. For example, our analysis explains why chain stores welcome trade promotions but independents do not. Our analysis outlines implications for managing trade promotions.
\end{abstract}

\section{Keywords}

channels of distribution, channel power, trade promotion, forward buying

\section{Disciplines}

Business | Marketing 


\title{
A Price Discrimination Model of Trade Promotions
}

\author{
Tony Haitao Cui Jagmohan S. Raju Z. John Zhang*
}

May 2007

Forthcoming, Marketing Science

\footnotetext{
${ }^{*}$ The authors thank the editor, the area editor and three reviewers for their thoughtful comments. Tony Haitao Cui is an Assistant Professor of Marketing at the Carlson School, University of Minnesota. Jagmohan S. Raju is Joseph J. Aresty Professor of Marketing at the Wharton School. Z. John Zhang is a Professor of Marketing at the Wharton School. Email correspondence: tcui@umn.edu, rajuj@wharton.upenn.edu, and zjzhang@wharton.upenn.edu.
} 


\title{
A Price Discrimination Model of Trade Promotions
}

\begin{abstract}
Critics have long faulted the wide-spread practice of trade promotions as wasteful. It has been estimated that this practice adds up to $\$ 100$ billion worth of inventory to the distribution system. Yet the practice continues. In this paper, we propose a price-discrimination model of trade promotions. We show that in a distribution channel characterized by a dominant retailer, a manufacturer has incentives to price-discriminate between the dominant retailer and smaller independents. While offering all retailers the same pricing policy, price-discrimination can be implemented through trade promotions as trade promotions induce different inventory-ordering behaviors on the part of retailers.

Differences in inventory holding costs have been shown to be an important determinant of consumer promotions. Our analysis suggests that differences in holding costs are also potentially an important driver for the use of trade promotions. The implications from our model explain a number of anecdotal and/or empirically observed puzzles about how trade promotions are practiced. For example, our analysis explains why chain stores welcome trade promotions but independents do not. Our analysis outlines implications for managing trade promotions. (Keyword: Channels of Distribution; Channel Power; Trade Promotion; Forward-Buying)
\end{abstract}




\section{Introduction}

According to the most recent estimate, consumer goods manufacturers in US spend about $\$ 85$ billion on trade promotions amounting to $13 \%$ of sales. In comparison, consumer promotions account for $6 \%$, and advertising and media spending only $4 \%$ of sales (Cannondale Associates 2002). Although trade promotions are widely used by manufacturers, they are often seen as wasteful. For example, Buzzell, Quelch, and Salmon (1990) argue that trade promotions impose severe administrative burdens on manufacturers and add huge inventory costs to distribution channels. ${ }^{1}$

Many have asked the question that if trade promotions are indeed inefficient, why are manufacturers still using them? A number of explanations have been proposed in the literature. It has been suggested that manufacturers face a Prisoners' Dilemma like situation - they have to offer trade promotions, otherwise the competition will take business away from them (e.g., Drèze and Bell 2003). Lal (1990) shows that national brand manufacturers could use trade promotions to limit the encroachment from a store brand. Lal, Little, and Villas-Boas (1996) suggest that allowing retailers to forward buy benefits competing manufacturers since forward buying decreases the intensity of competition between manufacturers. Agrawal (1996) analyzes the role of brand loyalty in determining optimal advertising policy (defensive strategy to build brand loyalty) and trade promotion policy (offensive strategy to steal customers from competition).

In this paper, we offer another explanation for trade promotions. Our explanation essentially establishes the price discrimination role of trade promotions in a channel context: manufacturers can use trade promotions to price discriminate between large retailers (e.g., chains) and small retailers (e.g., independents) by exploiting their different inventory carrying costs. Blattberg, Eppen, and Lieberman (1981) have shown that retailers can take advantage of the differences in consumers' inventory carrying costs. In this paper we show that manufacturers can similarly take advantage of the differences in retailers' inventory holding costs to achieve price discrimination through trade

\footnotetext{
${ }^{1}$ According to one estimate, $\$ 75$ - $\$ 100$ billion worth of inventory is added into US distribution channel because of trade promotions. See Kahn and McAlister, 1997, page 21.
} 
promotions.

However, price discrimination in a channel context is not a straightforward extension of that in a non-channel context, as multiple channel members are now involved in pricing and inventory decisions. More importantly, this price discrimination explanation for trade promotions results in a number of interesting predictions that are consistent with some of the otherwise puzzling observations in the area of trade promotions. For example, the predictions from our analysis explain why:

1. Manufacturers schedule their trade promotions well ahead to make it possible for retailers to plan forward buying.

2. Trade promotions are observed for packaged goods but not for perishable goods (Sellers 1992).

3. Chain stores are happier with trade promotions but independent and convenience stores not. ${ }^{2}$

4. Manufacturers allow forward buying but forbid diverting.

5. Manufacturers are complaining much more about trade promotions in recent years.

We believe that our ability to explain all these in the context of a parsimonious model suggests that the model is potentially useful. More specifically, in the context of a channel consisting of a single manufacturer and multiple retailers, we show that a manufacturer can effectively price discriminate among retailers by offering trade promotions if retailers have different inventory holding costs. The stores with lower holding costs and higher warehouse capacity (usually dominant retailers like chain stores and warehouse clubs) can benefit from forward buying. Interestingly, we further show that not only does the retailer with low holding costs benefit from trade promotions, but the retailer

\footnotetext{
${ }^{2}$ Independents and wholesalers who act as buying agents for independents always complain that trade promotions are not a fair practice for them (Zwiebach 1990, U.S. Distribution Journal 1992). For example, "Not surprisingly, in a broad survey of wholesalers, 87 percent agreed that the most urgent issue facing the wholesale-supplied system is fair and equal access to trade promotion funds." (U.S. Distribution Journal 1993b). On the other hand, chain stores benefit more from trade promotions and are happy with trade promotions (Progressive Grocer 2002, U.S. Distribution Journal 1993a). For instance, "Results also noted in the study show that wholesalers and their independent retail customers tend to benefit less from trade allowance programs than do other distribution channels." (U.S. Distribution Journal 1993a).
} 
with high holding costs can also benefit from this practice. Indeed, social welfare can also increase. Although we initially derive these results in a dominant retailer channel setting (Samuelson and Nordhaus 1989), we show in the technical appendix accompanying this paper (available on the Website of this journal) that these results hold in a more general competitive channel setting also. To the extent that a manufacturer can use trade promotions to price discriminate between retailers, Jeuland and Narasimhan (1985) is closely related to our study. However, our research differs from theirs. In their model, the retailers are not making pricing decisions. ${ }^{3}$ We explicitly model retailers' pricing decisions over time. Our model therefore takes the Jeuland and Narasimhan's analysis to the next logical step. This generalization yields interesting insights. One of these insights is that trade promotions can alleviate the double marginalization problem by giving the leading retailer more incentives to charge a lower retail price. ${ }^{4}{ }^{5}$ In addition, the model allows us to make some testable predictions about the practice of trade promotions.

The rest of the paper is organized as follows. The next section describes the dominant retailer model. The analysis in Section 3 consists of two parts. The first part outlines the benchmark case where the manufacturer is not allowed to offer trade promotions and analyzes the manufacturer's incentives to price discriminate between a dominant retailer and the competitive fringe. The second part derives the manufacturer's optimal trade promotion strategies and the retailers' optimal pricing and inventory decisions. Section 4 derives a number of interesting predictions regarding the effect of trade promotions on the manufacturer's profits, retailers' profits, and social welfare. Section 5 relaxes some assumptions used in the model. We conclude with a summary in Section 6 .

\footnotetext{
${ }^{3}$ In Jeuland and Narasimhan (1985), a seller could price discriminate between more intensely consuming and less intensely consuming customers by offering temporary price cuts. In order to make this section consistent with the rest of the paper, we are using "manufacturer" and "retailers" as in the rest of paper to represent the "seller" and "customers" in Jeuland and Narasimhan (1985), respectively. We thank anonymous Reviewer 3 for the suggestion.

${ }^{4}$ Double marginalization problem refers to the situation where the economic interests of upstream and downstream firms are not aligned such that the retail price facing end users is too high to maximize channel profits, as illustrated in Jeuland and Shugan (1983).

${ }^{5}$ Bruce, Desai and Staelin (2005) show that manufacturers of more durable products give deeper promotional discounts, which helps mitigate the double-marginalization problem. One of the differences between our research and theirs is that our research shows manufacturers can use trade promotions to alleviate double-marginalization through price discriminating between retailers. Their research shows that manufacturers selling a more durable product offer a greater depth of trade promotions and therefore have a less sever double marginalization problem.
} 


\section{The Model}

Consider a stylized channel where a manufacturer is selling a product through a dominant retailer (e.g., a chain store) and the competitive fringe (e.g., smaller independent retailers). The dominant retailer sets the retail price $(p)$, and the competitive fringe takes the retail price as the market price (Samuelson and Nordhaus 1989). ${ }^{6}$ We start with the dominant retailer model for three reasons. First, the phenomenon of "power retailers" is a familiar scene in today's retailing landscape and large retailers are becoming increasingly dominant in the marketplace. ${ }^{7} 8$ Second, large chains often assume the role of price leadership and exert pricing influence over smaller retailers (Raju and Zhang 2005). Third, the dominant retailer model simplifies the expositions considerably. As we show in Technical Appendix, if we were to relax the key assumption of only the dominant retailer setting the retail price and introduce price competition, our conclusions will not change qualitatively. ${ }^{9}$

The total market demand in each period is given by $Q=a-b p$, where $a>0$ and $b>0$ are constants. The dominant retailer faces a downward-sloping demand function given by

$$
Q_{d}=a-b_{1} p
$$

\footnotetext{
${ }^{6}$ Formally, the competitive fringe supplies at the quantity where the price equals the (rising) marginal cost.

${ }^{7}$ In the grocery industry, for example, mass merchandisers, warehouse clubs, and chain stores account for $23 \%$ of total grocery sales in 2002, while that number was only 9\% in 1995 (The McKinsey Quarterly 2003). Furthermore, the number of grocery chain stores in the U.S. was 18,400 in 1980, accounting for $52.7 \%$ of the total number of grocery stores. By 2003, the number of chain stores has mushroomed to 21,560 accounting for $65.4 \%$ of the total number of grocery stores. In the meantime, the share of dollar sales for chain stores increases from about $60.2 \%$ to $82.7 \%$. Not surprisingly, Independents shrank in number from 16,500 in 1980 to 11,421 in 2003 and their dollar sales percentage decreased from 39.8\% to 17.3\% (Progressive Grocer Annual Report 1981, 2003).

${ }^{8}$ There are several recent papers studying how the emergence of dominant retailers affects the interactions between channel members. In a bargaining model, Dukes, Gal-Or, and Srinivasan (2006) show that manufacturers may benefit from the increase in retailer dominance since channel efficiency can improve with dominant retailers gaining cost advantages. Geylani, Dukes, and Srinivasan (2005) show that a manufacturer has an incentive to engage in joint promotions and advertising with weaker retailers since the manufacturer gets a higher margin with weaker retailers than with dominant retailers, who has the power to dictate the wholesale price.

${ }^{9}$ In some industries, small stores can form cooperatives such as buying clubs to get promotional discounts from manufacturers or can make purchases from a middle party like a wholesaler, who buys from manufacturers for many small stores. The former case can be analyzed using the competitive model in Technical Appendix TA. The current paper is limited in analyzing the later case since we do not model a wholesaler between the manufacturer and retailers.
} 
The demand facing the competitive fringe in each period is correspondingly, ${ }^{10}$

$$
Q_{c}=Q-Q_{d}=\left(b_{1}-b\right) p
$$

In this dominant retailer channel, the competitive fringe's demand is increasing in retail price $p$ while the dominant retailer's is decreasing in $p$ such that these two different types of retailers do compete with each other. Figure 1 illustrates the demand functions at the retail level. We assume $b<b_{1} \leq \frac{3 b}{2}$ in our analysis to avoid any corner solution.

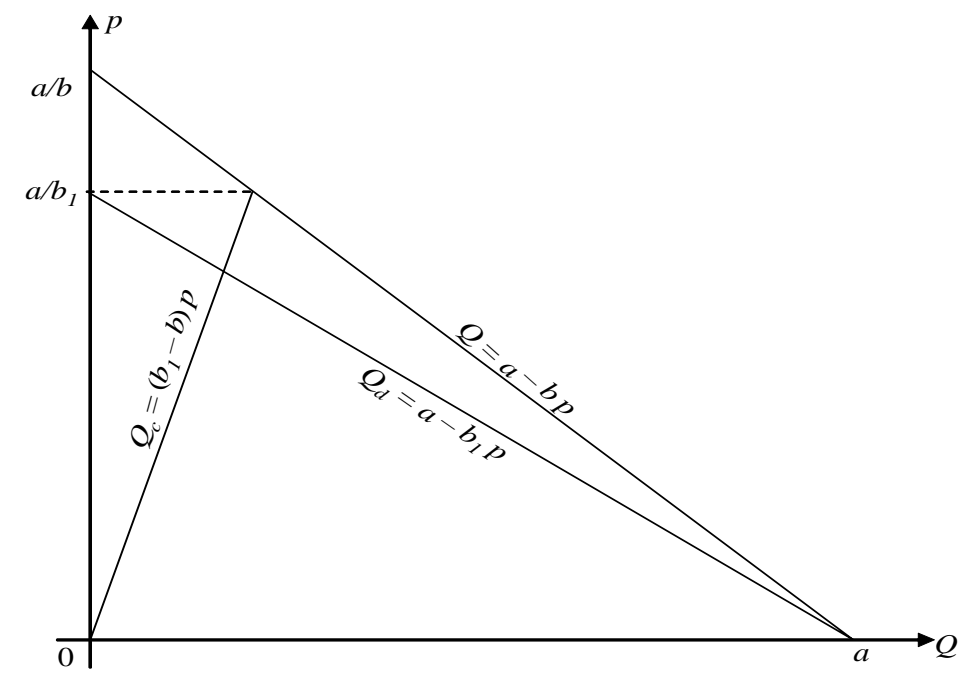

Figure 1: Retailers' Demands for $b<b_{1} \leq 1.5 b$

In this channel, all retailers incur a holding cost for any inventory carried from one period to the next. In practice, chain stores and warehouse clubs usually have lower inventory costs than independents. One reason could be a lower cost of capital. Further, chain stores and warehouse clubs also have higher inventory holding capacity and much more shelf space than independents, a big component of inventory holding costs, especially for food retailers (Blattberg, Eppen and Lieberman 1981). Therefore, it is reasonable to assume a lower inventory holding cost for the dominant retailer. ${ }^{11}$ We assume that the dominant retailer has a finite unit holding cost $\left(0 \leq h_{1}<\infty\right)$

\footnotetext{
${ }^{10} \mathrm{It}$ is worthy of noting that the competitive fringe in this paper is considered as a group of independents that is modeled as a single entity. Each independent in the competitive fringe is weak in terms of market power compared with the single dominant retailer. We thank anonymous Reviewer 3 for suggesting to make this point clear.

${ }^{11}$ Further, in Appendix A we also show that the dominant retailer has more incentives than retailers in the competitive fringe to reduce unit holding cost rate, since the economic reward from a unit of reduction in holding
} 
and retailers in the competitive fringe have an infinite unit holding cost $\left(h_{2}=\infty\right)$. It is important to note that the infinite inventory holding cost for a competitive fringe is only a simplifying assumption, and we relax the assumption in Technical Appendix where we allow a finite difference in the inventory holding costs between the dominant retailer and retailers from the competitive fringe. As the manufacturer's production costs do not affect our substantive conclusions, we set them equal to zero for simplicity.

Manufacturer's Decision Variables: The manufacturer in our model announces a wholesale price $w_{i}$ for each period $i$ within a pricing cycle consisting of $N$ periods $(i=1, \ldots, N) .{ }^{12}$ The length of the pricing cycle $N$ is also a manufacturer decision variable. The manufacturer's objective is to maximize the average profit per period within a pricing cycle. ${ }^{13}$

Dominant Retailer's Decision Variables: Conditional on the manufacturer's decisions on the length of a pricing cycle $(N)$ and the wholesale prices in each period within the cycle $\left(w_{1}, w_{2}, \ldots, w_{N}\right)$, the dominant retailer sets the retail price $p^{i}$ for periods $i=1,2, \ldots, N$ to maximize its total profit in each pricing cycle. As the dominant retailer has a finite holding cost, some inventory may be carried from one period to the next if forward buying is profitable. Therefore, the dominant retailer also makes decisions on $Q_{d}^{i, j}$, the inventory the dominant retailer orders in period $i$ and sells in period $j$, where $i, j \in\{1, \ldots, N\}$ and $i \leq j$.

Competitive Fringe's Decision Variables: Retailers in the competitive fringe take $p^{i}$ as the market price in each period $i$. As the holding cost for these retailers is assumed to be infinite, they do not carry any inventory from one period to the next. Therefore, a retailer in the competitive fringe will buy the product from the manufacturer and sell to customers if $w_{i} \leq p^{i}$ in period $i$.

cost rate is higher for the dominant retailer who makes forward buying than for the competitive fringe. Therefore, the dominant retailer will have a lower unit holding cost than the competitive fringe in the long run, which further validates our assumption.

${ }^{12}$ In this paper, we are modeling off-invoice trade promotions.

${ }^{13}$ For an early proof for the equivalence between maximizing average profit per period and maximizing total profit as discount factor approaches zero, see Jewell (1963). 
Mathematically, the manufacturer solves the following optimization problem

$$
\max _{w_{1}, w_{2}, \ldots, w_{N}, N} \quad\left[\frac{\sum_{i=1}^{N} w_{i}\left(\sum_{j=i}^{N} Q_{d}^{i, j}+Q_{c}^{i, i}\right)}{N}\right],
$$

where $Q_{d}^{i, j}$ denotes the inventory the dominant retailer orders in period $i$ and sells in period $j$, and $Q_{c}^{i, i}$ the inventory the retailers in the competitive fringe order and sell in period $i$. Of course, we have $Q_{c}^{i, j}=0$ for any $i \neq j$, as a competitive fringe does not carry any inventory. Given the manufacturer's wholesale prices and the length of pricing cycle $\left(w_{1}, w_{2}, \ldots, w_{N}, N\right)$, the dominant retailer's optimization is given by

$$
\max _{p^{1}, p^{2}, \ldots, p^{N}, Q_{d}^{i, j}}\left[\sum_{j=1}^{N} \sum_{i=1}^{j}\left[p^{j}-w_{i}-h_{1}(i-1)\right] Q_{d}^{i, j}\right] .
$$

We summarize the timing of decisions in this channel in Figure 2.

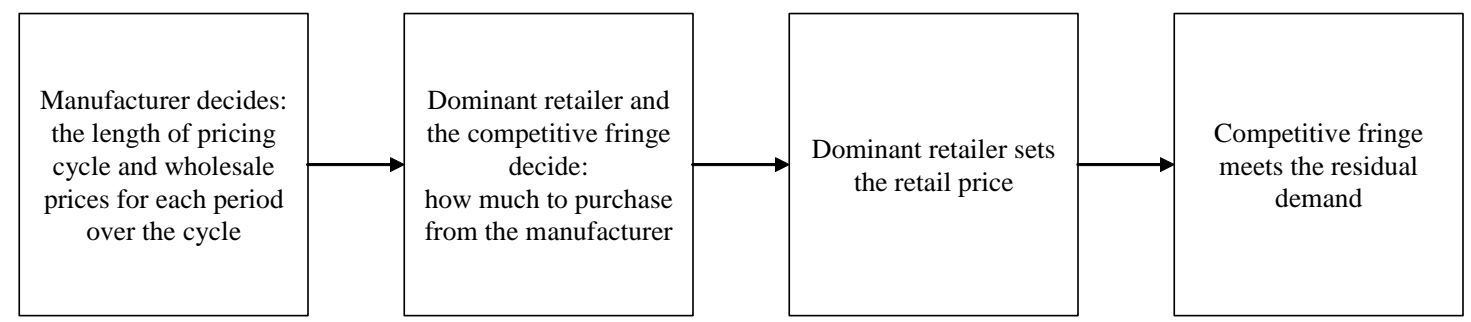

Figure 2: Timing of Decisions in Dominant Retailer Channel

The model specified above can result in a number of different pricing outcomes. Figure 3 illustrates several possible optimal wholesale price schedules. We define trade promotions as temporary price discounts offered by the manufacturer to retailers. Therefore, all the schedules except Case (a) in Figure 3 could be viewed as trade promotion schedules. For instance, in Figure 3(b), $w_{1}$ is the discounted wholesale price and $w_{2}$ is the regular wholesale price. If the manufacturer offers a low price in one period and charges higher and increasing prices for the following two periods as in $3(d)$, then $w_{1}$ and $w_{2}$ are both promotional wholesale prices and $w_{3}$ is the regular wholesale price. 

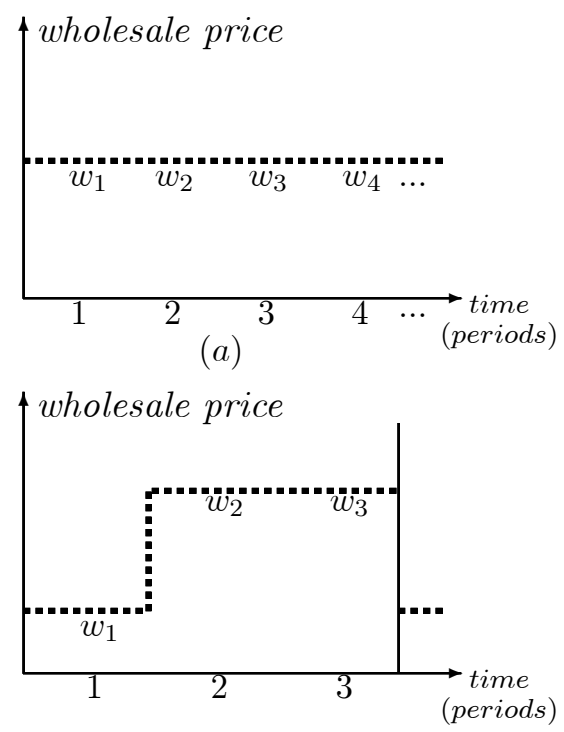

(c)

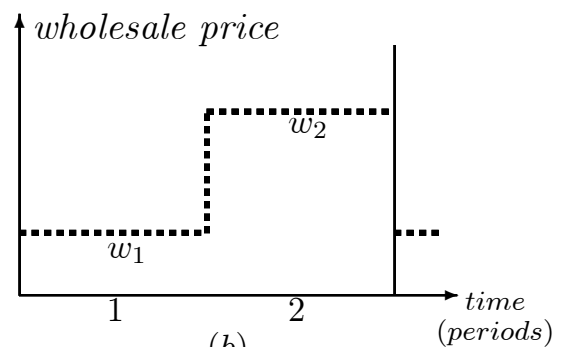

(b)

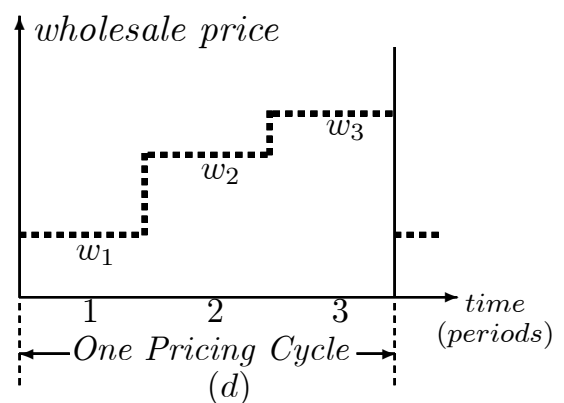

..... wholesale price

Figure 3: Examples of Optimal Wholesale Price Schedules

\section{Analysis}

We first show why the manufacturer has an incentive to price discriminate. We analyze the manufacturer's and the dominant retailer's pricing decisions, assuming that the manufacturer charges a time-invariant single wholesale price to all retailers. This case of no trade promotions is our benchmark for comparison with the case where the manufacturer offers trade promotions to the retailers. We will show that under some conditions, trade promotions can increase the manufacturer's profits as well as channel profits, even after accounting for the additional inventory costs that are added into the channel as a consequence of forward buying by the dominant retailer.

\subsection{Manufacturer's Incentives to Price Discriminate between Retailers}

If the manufacturer does not offer trade promotions, i.e., that the wholesale price is constant over time, all retailers will order from the manufacturer in each period and none will carry any inventory from one period to the next. The optimal prices and profits are easy to determine, and we simply state these in Lemma 1.

Lemma 1 If the manufacturer is restricted to offering a common time-invariant wholesale price 
to retailers, then the manufacturer will set its wholesale price at $w_{s}=\frac{a\left(2 b_{1}-b\right)}{2 b b_{1}}$ and the dominant retailer sets its retail price at $p_{s}=\frac{a\left(2 b_{1}+b\right)}{4 b b_{1}}$. The manufacturer's average sales and profit per period are given by $Q_{s}=\frac{a\left(2 b_{1}-b\right)}{4 b_{1}}$ and $\Pi_{s}=\frac{a^{2}\left(2 b_{1}-b\right)^{2}}{8 b b_{1}^{2}}$ respectively.

Proof of Lemma 1. Please see Appendix B. ${ }^{14}$

Of course, a single wholesale price is sub-optimal for the manufacturer for two reasons. First, the competitive fringe is passive in setting the retail price in the channel, and it will meet the residual demand as long as the wholesale price it has to pay is less or equal to the retail price set by the dominant retailer. Thus, ideally, the manufacturer wants to be able to charge the competitive fringe a higher wholesale price equal to the retail price so as to take away all the profits from the competitive fringe. Second, the manufacturer must also be mindful of the "double marginalization" problem dissipating channel profits because of too high a retail price. As only the dominant retailer's marginal cost will determine the retail price, if possible the manufacturer ideally wants to charge a lower wholesale price only to the dominant retailer. Therefore, to alleviate the double marginalization problem, and to take advantage of the price following behavior in the channel, it is in the manufacturer's interest to price discriminate between the dominant retailer and the competitive fringe. However, charging different wholesale prices to different retailers who are competing in the same market is unlawful. The manufacturer must find some other mechanisms to reap the benefits of price discrimination. Trade promotions, or time-variant wholesale prices, is one such pricing mechanism.

\subsection{Trade Promotions as A Mechanism to Price Discriminate}

When the manufacturer offers trade promotions, it offers the same wholesale prices to all retailers. Thus, nominally, the manufacturer does not price discriminate. However, as inventory holding costs differ among retailers, not all retailers can take advantage of trade promotions to the same degree. The retailers in the competitive fringe do not carry any inventory from one period to

\footnotetext{
${ }^{14}$ Unless stated otherwise, proofs for lemmas and propositions are provided in the Appendix at the end of this paper..
} 
the next, as their holding cost is assumed to be infinite (relaxed later). The dominant retailer finds it desirable to carry inventory acquired at the promotional wholesale price to those periods with higher wholesale prices, i.e. to forward buy, if its unit holding cost $\left(0 \leq h_{1}<\infty\right)$ is low enough. Because it is more profitable to buy in promotional periods and carry inventory forward, the effective wholesale prices are lower for the dominant retailer than for the competitive fringe. Thus, trade promotions enable the manufacturer to price discriminate.

In Lemma 2, we formalize this intuition, stating the manufacturer's and retailers' optimal strategies when trade promotions are offered in the channel.

Lemma 2 If the dominant retailer has a positive unit holding cost $\left(0<h_{1}<\infty\right)$, while the competitive fringe has an infinite unit holding cost $\left(h_{2}=\infty\right)$, then the manufacturer will offer the lowest wholesale price in the first period and charge an increasing wholesale price in each of the following $N-1$ periods within any $N$-period pricing cycle. The promotional wholesale price $w_{1}$ in the first period, the wholesale prices $w_{i}$ in the $i^{\text {th }}$ period $(2 \leq i \leq N)$, the retail price $p^{j}$ $(1 \leq j \leq N)$, dominant retailer's sales $Q_{d j}$ in the $j^{\text {th }}$ period, competitive fringe's sales $Q_{c j}$ in the $j^{\text {th }}$ period, average sales per period $Q_{h_{1}}$, and the manufacturer's average profit per period $\Pi_{h_{1}}$ are respectively given by

$$
\begin{cases}w_{1}=\frac{N\left[4 a b_{1}-2 a b-b_{1} b h_{1}(N-1)\right]}{\left.2 b_{1} b(N+1)+b_{1}(N-1)\right]} & \\ w_{i}=\frac{a+b_{1} w_{1}+b_{1} h_{1}(i-1)}{2 b_{1}} & i=2, \ldots, N \\ p^{j}=\frac{a+b_{1} w_{1}+b_{1} h_{1}(j-1)}{2 b_{1}} & j=1, \ldots, N \\ Q_{d j}=\frac{a-b_{1} w_{1}-b_{1} h_{1}(j-1)}{2} & j=1, \ldots, N \\ Q_{c j}=\frac{\left(b_{1}-b\right)\left[a+b_{1} w_{1}+b_{1} h_{1}(j-1)\right]}{2 b_{1}} & j=1, \ldots, N \\ Q_{h_{1}}=\frac{1}{4 b_{1}}\left[4 a b_{1}-2 a b-2 b b_{1} w_{1}-b b_{1} h_{1}(N-1)\right] & \\ \Pi_{h_{1}}=\frac{1}{N}\left[w_{1} \sum_{j=1}^{N} Q_{d j}+\sum_{i=1}^{N} w_{i} Q_{c i}\right] & \end{cases}
$$

and we also have

$$
\left\{\begin{array}{ll}
w_{i}=p^{i} & i=2, \ldots, N \\
p^{i}-p^{i-1}=\frac{h_{1}}{2} & i=2, \ldots, N
\end{array} .\right.
$$

Figure 4 shows the manufacturer's and the retailer's optimal prices within a pricing cycle when $N$ is equal to 5 . The retail price will be raised by $\frac{h_{1}}{2}$ per period, as the dominant retailer's effective 


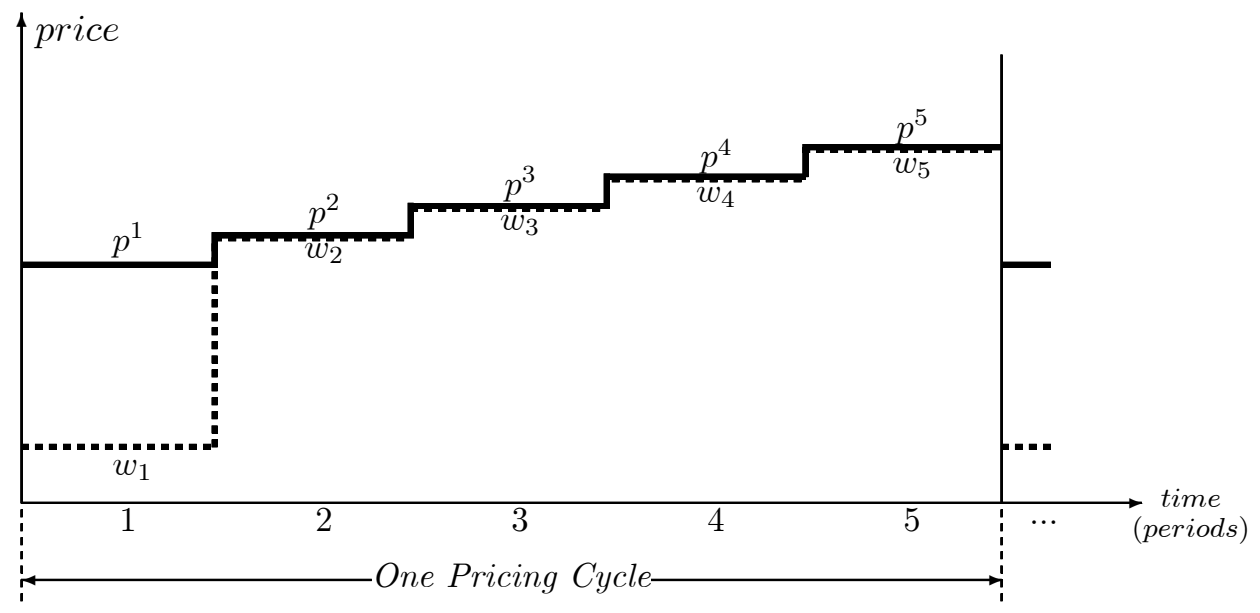

retail price

..... wholesale price

Figure 4: Optimal Wholesale and Retail Prices within A Pricing Cycle for $N=5$

unit acquisition cost increases at the rate of $h_{1}$ per period. ${ }^{15}$ The manufacturer also raises the wholesale price by the same amount to take the surplus away from the competitive fringe. Thus, at any off-promotion period, the dominant retailer prefers to lower its price in the current period to sell more, instead of carrying any inventory forward to the next period. The manufacturer charges a wholesale price equal to the retail price in period $i(i=2, \ldots, N)$ in order to get all surplus from the competitive fringe. To determine the length of pricing cycle $N$, the manufacturer solves the optimization problem:

$$
\begin{array}{ll}
\max _{N} & \Pi_{h_{1}}(N) \\
\text { s.t. } & w_{1}+(i-1) h_{1} \leq w_{i}, \quad i=1, \ldots, N \\
& w_{1}=\frac{N\left[4 a b_{1}-2 a b-b_{1} b h_{1}(N-1)\right]}{2 b_{1}\left[b(N+1)+b_{1}(N-1)\right]} \\
& w_{i}=\frac{a+b_{1} w_{1}+b_{1} h_{1}(i-1)}{2 b_{1}}, \quad i=2, \ldots, N \\
N \geq 1 .
\end{array}
$$

\footnotetext{
${ }^{15}$ As we show in Extensions, it is not necessary for wholesale prices to increase every period in order for the manufacturer to price discriminate between retailers. Two price points are sufficient for price discrimination to occur and allow the manufacturer to capture the bulk of the benefits from trade promotions.
} 
The constraints $w_{1}+(i-1) h_{1} \leq w_{i}$ guarantee that the dominant retailer's effective unit acquisition cost of the items sold in period $i=2, \ldots, N$ is no higher than the wholesale price in the same period, so that the dominant retailer does not find it worthwhile to purchase from the manufacturer in period $i$ at the current wholesale price. As the dominant retailer's effective acquisition cost per unit is increasing at a faster rate $\left(h_{1}\right.$ per period $)$ than the wholesale price $\left(\frac{h_{1}}{2}\right.$ per period $)$ over time, there is an upper limit for $N$ beyond which it is not profitable for the dominant retailer to carry any inventory. The constraints thus provide an upper bound on the manufacturer's decision variable $N$. As the range for $N$ is convex and compact, there always exists a solution to the optimization problem (3.3). Given the optimal $N$ and the sequence of wholesale prices preannounced by the manufacturer, retailers will not carry any inventory from one pricing cycle to the next since the first period in the next pricing cycle will be a promotional period again. The manufacturer's decisions on $N$ and the sequence of wholesale prices in a pricing cycle will therefore not depend on its decisions in any other pricing cycles. In Appendix C, we show that the manufacturer's announcement of both the length of pricing cycles $N$ and the sequence of wholesale prices is credible. The manufacturer has no incentive in any period within a pricing cycle to deviate from the preannounced $N$ and wholesale prices. ${ }^{16}$ This suggests that both the manufacturer's and retailers' behaviors are independent between pricing cycles.

It follows from the analysis above that the effective unit acquisition cost for the dominant retailer is lower than that for the competitive fringe in period $i=2, \ldots, N$, or $w_{1}+h_{1}(i-1)<w_{i}$ for $i=2, \ldots, N$. This leads to our first Proposition.

Proposition 1 The manufacturer can use trade promotions to price discriminate between retailers who have different inventory holding costs.

Proposition 1 formally suggests a new justification for trade promotions not previously recognized in the literature. While offering the same wholesale price to all retailers but varying it over

\footnotetext{
${ }^{16}$ We thank AE and anonymous Reviewers 1 and 4 for pointing out this to us. In practice, the manufacturer can also credibly commit to a sequence of prices because of reputation factors, legal factors, etc.
} 
time, the manufacturer can price discriminate between retailers who are competing in the same market, as long as the retailer(s) with high wholesale price sensitivity has lower unit inventory holding costs than the retailer(s) with low wholesale price sensitivity. Because of the ability to price discriminate, the manufacturer can profit from trade promotions. This perhaps explains the paradoxical trend, as noted by Ailawadi, Farris, and Shames (1999), that "at the peak of the tradepromotion controversy, manufacturers' profits increased at a fairly steady rate, whereas retailers' profits were stable at best.

Our analysis also sheds some light on why manufacturers typically "allow" forward buying, but vehemently oppose any "diversion". Our analysis suggests that forward buying makes pricediscrimination possible, but diversion weakens the price discrimination mechanism. Furthermore, Proposition 1 suggests that trade promotions could also alleviate the double marginalization problem. Therefore, the channel as a whole could benefit from such a practice because the manufacturer can induce the dominant retailer to set a lower retail price by charging the dominant retailer with a lower wholesale price - a lower retail price increases channel profits in a dyadic channel where the linear wholesale price contract is in use. Indeed, such benefits can be substantial, as we will show through numerical analyses next.

\section{Effects of Trade Promotions}

A preliminary examination of the value of the price discrimination explanation for trade promotions can be made based on its ability to explain how trade promotions are practiced. To this end, we conducted numerical analyses to show the possible effects of trade promotions on players' profits and social welfare. The results from the numerical analyses are limited in their generalizability, but sufficient to motivate potential explanations for: 1) why trade promotions are frequently observed for packaged goods but rarely observed for perishable goods; 2) why chain stores are happy with trade promotions but independent and convenience stores are not; and 3) why manufacturers started complaining about the effectiveness of trade promotions as retailers became larger. 
Table 1 lists the parameters used in the numerical study. We discuss our findings in detail in the following subsections.

Table 1: Values of Parameters in Numerical Analyses

\begin{tabular}{|c|c|}
\hline Parameters & Values \\
\hline$a$ & 1 \\
\hline$b$ & 1 \\
\hline$h_{1}$ & $0.0005,0.005,0.01,0.02,0.03,0.04,0.05,0.06,0.07,0.08,0.09,0.10,0.11,0.12$ \\
\hline$h_{2}$ & $+\infty$ \\
\hline$b_{1}$ & $1.00,1.05,1.10,1.15,1.20,1.25,1.30,1.35,1.40,1.45,1.50$ \\
\hline
\end{tabular}

Manufacturer's Incentives to Offer Trade Promotions: Intuitively, all else being equal, the manufacturer will be more willing to offer trade promotions to retailers as a price discrimination mechanism if the dominant retailer has a lower unit holding cost. Furthermore, the incidence of trade promotions also depends on the size of the dominant retailer. All else being equal, if $b_{1}$ is smaller $\left(b_{1}\right.$ closes to $\left.b\right)$, the manufacturer has less of an incentive to offer trade promotions since the dominant retailer is selling a bigger proportion of the total demand. The benefits from inducing the dominant retailer to charge a lower retail price will not offset the cost. If $b_{1}$ is larger $\left(b_{1}\right.$ closes to $\left.\frac{3 b}{2}\right)$, the manufacturer also has less of an incentive to offer trade promotions. This is because a larger $b_{1}$ gives the dominant retailer the incentive to charge a lower retail price, as a large $b_{1}$ implies a high consumer price sensitivity. Only for the intermediate values of $b_{1}$, the manufacturer will be willing to use trade promotions to price discriminate between the dominant retailer and the retailers in the competitive fringe. Figure 5 and Result 1 below confirm these intuitions.

Result 1 Trade promotions can be profitable to the manufacturer when the dominant retailer's unit holding cost $h_{1}$ is sufficiently low at any given $b_{1}$. At any given $h_{1}$, the manufacturer has incentives to offer trade promotions when the dominant retailer is sufficiently dominant, but not overly dominant ( $b_{1}$ is of an intermediate value). 


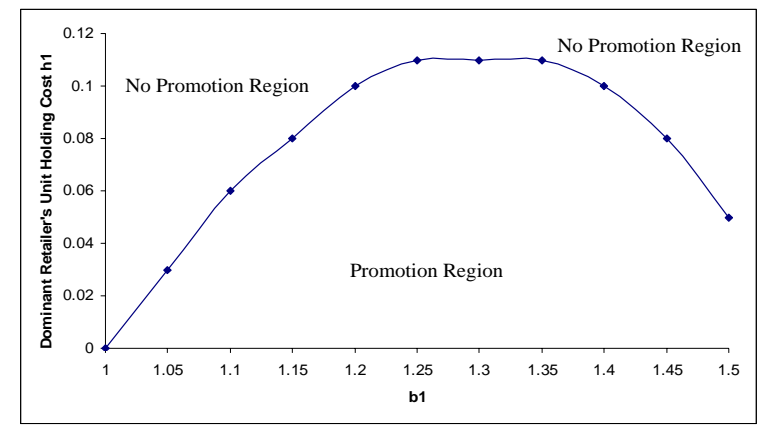

Figure 5: Manufacturer's Promotion Boundary

Result 1 suggests that trade promotions are not always beneficial to the manufacturer. Only in those channel settings where the dominant retailer is not too dominant, or inventory holding costs vary sufficiently among retailers, are trade promotions beneficial to the manufacturer. This suggests that one is less likely to observe trade promotions in product categories, such as produce and frozen foods, where the holding costs for these products are quite high and similar for both chain stores and independents. The easy-to-store items such as canned food or detergents, however, are expected to have more shipments on trade promotions.

Result 1 also suggests that the presence of a very dominant retailer (very low $b_{1}$ ) in a distribution channel is not conducive to the functioning of trade promotions as a price discrimination mechanism. At any given inventory holding cost $h_{1}$, the more dominant the dominant retailer is in a channel, the less likely the manufacturer will resort to trade promotions. This suggests that one is less likely to observe trade promotions in product categories such as toys and office supplies where power retailers significantly dominate.

Effects of Trade Promotions on Sales: A lower $h_{1}$ can facilitate price discrimination through trade promotions. Sales are therefore expected to increase with a smaller $h_{1}$. When the dominant retailer has a smaller $b_{1}$ or equivalently a larger demand share, the manufacturer will have a lower incentive to offer trade promotions. When $b_{1}$ is small, the double marginalization problem is worse, and sales do not increase as much. 
Table 2: Increase in Sales under Multiple-Wholesale-Price Strategy Relative to Single-WholesalePrice Strategy (\%)

\begin{tabular}{|c|c|c|c|c|c|c|c|c|c|c|c|c|c|c|c|}
\hline & \multicolumn{14}{|c|}{ holding cost h1 } \\
\hline & & 0.0005 & 0.005 & 0.01 & 0.02 & 0.03 & 0.04 & 0.05 & 0.06 & 0.07 & 0.08 & 0.09 & 0.1 & 0.11 & 0.12 \\
\hline \multirow{11}{*}{ b1 } & 1 & $0.00 \%$ & $0.00 \%$ & $0.00 \%$ & $0.00 \%$ & $0.00 \%$ & $0.00 \%$ & $0.00 \%$ & $0.00 \%$ & $0.00 \%$ & $0.00 \%$ & $0.00 \%$ & $0.00 \%$ & $0.00 \%$ & $0.00 \%$ \\
\hline & 1.05 & $1.97 \%$ & $1.11 \%$ & $0.67 \%$ & $0.27 \%$ & $-0.21 \%$ & $0.00 \%$ & $0.00 \%$ & $0.00 \%$ & $0.00 \%$ & $0.00 \%$ & $0.00 \%$ & $0.00 \%$ & $0.00 \%$ & $0.00 \%$ \\
\hline & 1.1 & $4.12 \%$ & $2.89 \%$ & $2.19 \%$ & $1.33 \%$ & $1.03 \%$ & $0.56 \%$ & $0.09 \%$ & $-0.38 \%$ & $0.00 \%$ & $0.00 \%$ & $0.00 \%$ & $0.00 \%$ & $0.00 \%$ & $0.00 \%$ \\
\hline & 1.15 & $6.21 \%$ & $4.71 \%$ & $3.93 \%$ & $2.91 \%$ & $1.98 \%$ & $1.78 \%$ & $1.32 \%$ & $0.86 \%$ & $0.41 \%$ & $-0.05 \%$ & $0.00 \%$ & $0.00 \%$ & $0.00 \%$ & $0.00 \%$ \\
\hline & 1.2 & $8.23 \%$ & $6.51 \%$ & $5.57 \%$ & $4.43 \%$ & $3.52 \%$ & $2.97 \%$ & $2.52 \%$ & $2.07 \%$ & $1.62 \%$ & $1.17 \%$ & $0.72 \%$ & $0.27 \%$ & $0.00 \%$ & $0.00 \%$ \\
\hline & 1.25 & $10.17 \%$ & $8.31 \%$ & $7.27 \%$ & $5.86 \%$ & $5.00 \%$ & $4.10 \%$ & $3.68 \%$ & $3.24 \%$ & $2.79 \%$ & $2.35 \%$ & $1.91 \%$ & $1.47 \%$ & $1.03 \%$ & $0.00 \%$ \\
\hline & 1.3 & $12.04 \%$ & $10.02 \%$ & $8.85 \%$ & $7.43 \%$ & $6.43 \%$ & $5.55 \%$ & $4.80 \%$ & $4.37 \%$ & $3.93 \%$ & $3.50 \%$ & $3.07 \%$ & $2.63 \%$ & $2.20 \%$ & $0.00 \%$ \\
\hline & 1.35 & $13.84 \%$ & $11.70 \%$ & $10.49 \%$ & $8.94 \%$ & $7.82 \%$ & $6.94 \%$ & $6.06 \%$ & $5.47 \%$ & $5.04 \%$ & $4.61 \%$ & $4.18 \%$ & $3.76 \%$ & $3.33 \%$ & $0.00 \%$ \\
\hline & 1.4 & $15.56 \%$ & $13.30 \%$ & $12.06 \%$ & $10.41 \%$ & $9.16 \%$ & $8.29 \%$ & $7.42 \%$ & $6.55 \%$ & $6.12 \%$ & $5.70 \%$ & $5.27 \%$ & $4.85 \%$ & $0.00 \%$ & $0.00 \%$ \\
\hline & 1.45 & $17.22 \%$ & $14.89 \%$ & $13.58 \%$ & $11.82 \%$ & $10.51 \%$ & $9.59 \%$ & $8.73 \%$ & $7.59 \%$ & $7.17 \%$ & $6.75 \%$ & $0.00 \%$ & $0.00 \%$ & $0.00 \%$ & $0.00 \%$ \\
\hline & 1.5 & $18.82 \%$ & $16.41 \%$ & $15.04 \%$ & $13.17 \%$ & $11.88 \%$ & $10.86 \%$ & $10.00 \%$ & $0.00 \%$ & $0.00 \%$ & $0.00 \%$ & $0.00 \%$ & $0.00 \%$ & $0.00 \%$ & $0.00 \%$ \\
\hline
\end{tabular}

Table 2 shows the percentage increase in the manufacturer's sales by using multiple wholesale prices as opposed to the sales by using single wholesale price, i.e., $\frac{Q_{h_{1}}-Q_{s}}{Q_{s}} \times 100 \%$ where $Q_{s}=$ $\frac{a\left(2 b_{1}-b\right)}{4 b_{1}}$ as shown in Lemma 1. This leads to the result below.

Result 2 Increase in average sales per period can decrease in the dominant retailer's holding cost $h_{1}$ given $b_{1}$, and is increasing in the dominant retailer's price sensitivity parameter $b_{1}$ given $h_{1}$.

Result 2 and Table 2 suggest that when the manufacturer uses trade promotions to price discriminate between retailers, its sales can increase due to the reduced retail price, and such an increase is larger for a smaller $h_{1}$ and/or a larger $b_{1}$. As shown in Accenture (2001), 95\% of the interviewed manufacturers cite "Increase Store Sales" as the top reason for trade promotions. ${ }^{17}$ Result 2 and Table 2 provide a potential rationale for such an almost unanimous citation from manufacturers about the reasons for trade promotions.

Effects of Trade Promotions on Profits: As a lower $h_{1}$ facilitates price discrimination through trade promotions, the manufacturer's profits are expected to increase with a smaller $h_{1} \cdot{ }^{18}$ When

\footnotetext{
${ }^{17}$ The 2004 ACNielsen Report on Trade Promotions shows similar result: the top three reasons for manufacturers to run trade promotions are "increase sales volume", "increase market share", and "maintain current volume" that together account for $83 \%$ of responses (ACNielsen 2004).

${ }^{18}$ Our numerical study shows that $N$ is decreasing in $h_{1}$ and increasing in $b_{1}$.
} 
Table 3: Increase in The Manufacturer's Profit under Multiple-Wholesale-Price Strategy Relative to Single-Wholesale-Price Strategy (\%)

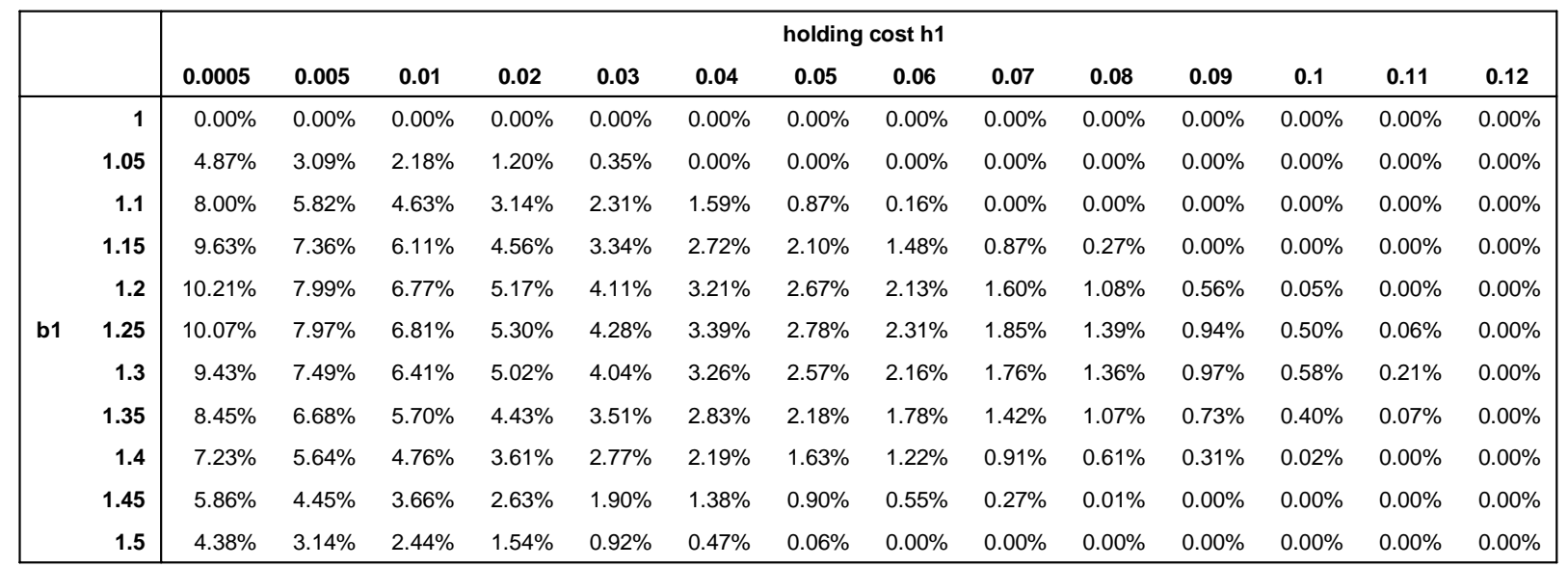

the dominant retailer has a larger demand share (a smaller $b_{1}$ ), the profitability of trade promotions for the manufacturer is decreasing, as there is less surplus the manufacturer could take from the competitive fringe through price discrimination. Table 3 shows the percentage increase in the manufacturer's profit by using multiple wholesale prices as opposed to a single wholesale price, i.e., $\frac{\Pi_{h_{1}}-\Pi_{s}}{\Pi_{s}} \times 100 \%$ where $\Pi_{s}=\frac{a^{2}\left(2 b_{1}-b\right)^{2}}{8 b b_{1}^{2}}$ as shown in Lemma 1 . This leads to the result below.

Result 3 The increased profits from trade promotions as opposed to a single wholesale price for the manufacturer are decreasing in the dominant retailer's holding cost $h_{1}$, and has an inverted- $U$ relationship with the dominant retailer's price sensitivity parameter $b_{1}$.

Result 3 provides a potential rationale for the vocal complaints in recent years by the manufacturers regarding the effectiveness of trade promotions. As dominant retailers such as chain stores and warehouse clubs become larger ( $\left.\operatorname{small} b_{1}\right)$, the benefits of trade promotions to the manufacturer decrease. It is such a change that prompts some manufacturers to re-evaluate the effectiveness of their trade promotions. From this perspective, it is easy to see why practitioners recognize that "success (of trade promotions) will be elusive unless independents are involved" and as far as the effectiveness of trade promotions is concerned, manufacturers "need a strong, viable independent sector" (Progressive Grocer Annual Report 2000, page 30). 
We can also examine how retailers' profitability is affected by the same parameters $h_{1}$ and $b_{1}$. We summarize our results below.

Result 4 The benefits from trade promotions for the dominant retailer can decrease in its holding cost $h_{1}$ and have an inverted- $U$ relationship with $b_{1}$. The competitive fringe retailers can become either worse off or better off due to trade promotions. Their gain from trade promotions can increase with $h_{1}$ and can have a $U$-shaped relationship with $b_{1}$.

Intuitively, as the holding cost $h_{1}$ is a direct cost to the dominant retailer, a higher $h_{1}$ will reduce the dominant retailer's profit. Our analysis shows that the increase in the dominant retailer's profits has the highest value for the intermediate values of $b_{1}$ (Figure 6 in Technical Appendix TB verifies this result). The intuition for this is as follows. The dominant retailer's profits are affected by two factors. One is the average profit from each unit sold, and the other is the total number of units sold. When $b_{1}$ is large (close to $\frac{3 b}{2}$ ), the manufacturer offers a higher promotional depth relative to the single-wholesale-price strategy (see Table 4) and the increase in the dominant retailer's average profit from each sale as opposed to the single-wholesale-price strategy gets higher. However, for any $p$, its demand share is small for a large $b_{1}$. The effect of a small demand share dominates the effect of a high average profit from each sale and, therefore, the dominant retailer's profit is low for a large $b_{1}$. When $b_{1}$ is small (close to $b$ ), the dominant retailer has a large portion of demand, but the average profit from each sale is small, as the manufacturer offers a higher $w_{1}$. Thus, the dominant retailer's profits will again be small. Therefore, the dominant retailer's profit is first increasing, and then decreasing with $b_{1}$.

The numerical study also suggests that the pricing cycle will be shorter ( $N$ is smaller) for a higher $h_{1}$. As the first period within a pricing cycle is the only period during which the retailers in the competitive fringe can make a profit, they will have higher average profits with shorter pricing cycles, implying that the competitive fringe's profit increases in $h_{1}$. 
Table 4: Promotional Depth under Multiple-Wholesale-Price Strategy Relative to Single-WholesalePrice Strategy (\%)

\begin{tabular}{|c|c|c|c|c|c|c|c|c|c|c|c|c|c|c|c|}
\hline & \multicolumn{14}{|c|}{ holding cost h1 } \\
\hline & & 0.0005 & 0.005 & 0.01 & 0.02 & 0.03 & 0.04 & 0.05 & 0.06 & 0.07 & 0.08 & 0.09 & 0.1 & 0.11 & 0.12 \\
\hline \multirow{11}{*}{ b1 } & 1 & $0.00 \%$ & $0.00 \%$ & $0.00 \%$ & $0.00 \%$ & $0.00 \%$ & $0.00 \%$ & $0.00 \%$ & $0.00 \%$ & $0.00 \%$ & $0.00 \%$ & $0.00 \%$ & $0.00 \%$ & $0.00 \%$ & $0.00 \%$ \\
\hline & 1.05 & $2.50 \%$ & $2.54 \%$ & $2.58 \%$ & $2.18 \%$ & $2.65 \%$ & $0.00 \%$ & $0.00 \%$ & $0.00 \%$ & $0.00 \%$ & $0.00 \%$ & $0.00 \%$ & $0.00 \%$ & $0.00 \%$ & $0.00 \%$ \\
\hline & 1.1 & $4.81 \%$ & $4.73 \%$ & $4.94 \%$ & $5.00 \%$ & $3.78 \%$ & $4.23 \%$ & $4.67 \%$ & $5.12 \%$ & $0.00 \%$ & $0.00 \%$ & $0.00 \%$ & $0.00 \%$ & $0.00 \%$ & $0.00 \%$ \\
\hline & 1.15 & $7.01 \%$ & $6.92 \%$ & $6.58 \%$ & $6.45 \%$ & $7.29 \%$ & $5.32 \%$ & $5.75 \%$ & $6.17 \%$ & $6.60 \%$ & $7.03 \%$ & $0.00 \%$ & $0.00 \%$ & $0.00 \%$ & $0.00 \%$ \\
\hline & 1.2 & $9.09 \%$ & $9.08 \%$ & $8.99 \%$ & $7.86 \%$ & $8.66 \%$ & $6.39 \%$ & $6.80 \%$ & $7.21 \%$ & $7.62 \%$ & $8.03 \%$ & $8.44 \%$ & $8.84 \%$ & $0.00 \%$ & $0.00 \%$ \\
\hline & 1.25 & $11.09 \%$ & $10.81 \%$ & $10.61 \%$ & $10.86 \%$ & $10.00 \%$ & $10.77 \%$ & $7.84 \%$ & $8.24 \%$ & $8.63 \%$ & $9.02 \%$ & $9.41 \%$ & $9.80 \%$ & $10.20 \%$ & $0.00 \%$ \\
\hline & 1.3 & $13.01 \%$ & $12.86 \%$ & $12.92 \%$ & $12.30 \%$ & $11.31 \%$ & $12.05 \%$ & $8.87 \%$ & $9.24 \%$ & $9.62 \%$ & $10.00 \%$ & $10.38 \%$ & $10.76 \%$ & $11.13 \%$ & $0.00 \%$ \\
\hline & 1.35 & $14.83 \%$ & $14.48 \%$ & $14.46 \%$ & $13.71 \%$ & $12.58 \%$ & $13.29 \%$ & $14.00 \%$ & $10.24 \%$ & $10.60 \%$ & $10.97 \%$ & $11.33 \%$ & $11.70 \%$ & $12.06 \%$ & $0.00 \%$ \\
\hline & 1.4 & $16.57 \%$ & $16.42 \%$ & $15.95 \%$ & $15.07 \%$ & $13.82 \%$ & $14.51 \%$ & $15.20 \%$ & $11.21 \%$ & $11.57 \%$ & $11.92 \%$ & $12.27 \%$ & $12.63 \%$ & $0.00 \%$ & $0.00 \%$ \\
\hline & 1.45 & $18.25 \%$ & $17.94 \%$ & $17.40 \%$ & $16.40 \%$ & $17.38 \%$ & $15.70 \%$ & $16.36 \%$ & $12.17 \%$ & $12.51 \%$ & $12.86 \%$ & $0.00 \%$ & $0.00 \%$ & $0.00 \%$ & $0.00 \%$ \\
\hline & 1.5 & $19.83 \%$ & $19.41 \%$ & $18.79 \%$ & $19.17 \%$ & $18.63 \%$ & $16.86 \%$ & $17.50 \%$ & $0.00 \%$ & $0.00 \%$ & $0.00 \%$ & $0.00 \%$ & $0.00 \%$ & $0.00 \%$ & $0.00 \%$ \\
\hline
\end{tabular}

The competitive fringe gets the lowest profit for intermediate values of $b_{1}$ and more profits for smaller and larger $b_{1}$ 's as expected. Also note that for a large $b_{1}$ and a large $h_{1}$, the competitive fringe could become better off due to trade promotions. For a given $b_{1}$, it is optimal for the manufacturer to choose a shorter pricing cycle when $h_{1}$ goes up. Thus, the promotional period 1 , when the competitive fringe can get positive surplus, will occur more frequently as $h_{1}$ becomes larger and the competitive fringe becomes better off as a result. For a given $h_{1}$, the manufacturer will offer a lower $w_{1}$ but will choose a longer pricing cycle when $b_{1}$ becomes larger. When $b_{1}$ is very large, the positive effect of a lower $w_{1}$ on the competitive fringe's profits will dominate the negative effect of a longer pricing cycle and the competitive fringe becomes better off. Therefore, the competitive fringe's profit is first decreasing, and then increasing in $b_{1}$.

Effects of Trade Promotions on Social Welfare: Many researchers have argued that trade promotions are harmful to a channel because of increased inventory holding costs. Although our model also suggests that trade promotions increase inventory holding costs, we find that trade promotions can potentially benefit the system as a whole by enabling the manufacturer to price discriminate between retailers. We state this result formally below (Figure 7 in Technical Appendix TB verifies this result). 
Result 5 Trade promotions can increase social welfare. The increase in social welfare is smaller when the dominant retailer's holding cost $h_{1}$ is larger or $b_{1}$ is smaller (or the dominant retailer is more dominant).

The source of the welfare improvement comes from the fact that price discrimination can alleviate the problem of double marginalization in the channel, to the benefit of not only the manufacturer and the retailers, but also the consumers. Trade promotions induce the dominant retailer to choose a low retail price. Although the retail price goes up by $\frac{h_{1}}{2}$ per period because of the presence of the holding cost $h_{1}$, the retail prices in most periods will be lower than the benchmark retail price $p_{s}=\frac{a\left(2 b_{1}+b\right)}{4 b b_{1}}$, the retail price that the dominant retailer would set if the manufacturer were to charge all retailers the same time-invariant wholesale price $w_{s}=\frac{a\left(2 b_{1}-b\right)}{2 b b_{1}}$. Interestingly, competitive fringe may even benefit from trade promotions as shown above. This is because the channel profit increases as the double marginalization problem is lessened and all channel members, including the competitive fringe, can benefit from increased channel sales. Even when the competitive fringe becomes worse-off due to price discrimination, the total social welfare can still increase because of the lower retail price set by dominant retailer. Consequently, trade promotions can improve channel efficiency and increase social welfare.

Overall, what emerges from Proposition 1 and Results 1-5 is a different perspective on trade promotions. Manufacturers embrace trade promotions because the practice allows them to implement price discrimination in a distribution channel. In light of this perspective, it is rather understandable that when manufacturers run trade promotions, they allow forward buying, but disallow diversion. Our model can also explain why retailers do not all endorse this practice. The dominant retailer favors such a practice as it stands to benefit from trade promotions due to its low inventory holding costs. The competitive fringe could oppose such a practice, as it may become worse off because of the effective price discrimination that trade promotions achieve. However, this does not mean that such a practice is harmful because social welfare can increase with this practice. Finally, manufacturers may have incentives to abandon this practice, as the retail 
consolidation continues. ${ }^{19}$

\section{Extensions}

Our basic model leaves three important questions unanswered so far.

1. Does price-discrimination necessarily require multiple wholesale prices, as suggested by the solution to the optimization problem (3.3)? If it does, such a theory would be rather counterfactual, as in practice, we often observe manufacturers alternating between two wholesale prices in a given period of time: the regular and discounted wholesale prices.

2. Does a price discrimination explanation of trade promotions also hold in the situations where the competitive fringe has finite (as oppose to infinite) inventory holding costs?

3. Does the price discrimination explanation of trade promotions depend on the assumption of dominant retailer channel (i.e., only the dominant retailer has pricing power)? In other words, if the competitive fringe independently and competitively sets its retail price, would the manufacturer's incentives to use trade promotions to price discriminate go away?

\subsection{Comparing 2-Price Model with the Full Model}

In our basic model, as the optimal solution, the manufacturer's wholesale price increases every period, after the initial dip, over the rest of the pricing cycle. This feature of our solution is not necessary as two price points are sufficient for price discrimination to occur. In fact, there are three ways to reconcile our optimal solution with the frequently observed trade promotion practice of two price points. First, the parameters may be such that the optimal solution calls for a regular wholesale price and a discounted price. In other words, there is a possibility that a 2-price solution

\footnotetext{
${ }^{19}$ This may well explain why the portion of trade promotion budgets allocated to off-invoice allowances has decreased from about 90 percent in mid-1990s to about 35 percent in recent years (Cannondale Associates 2003), but chain retailers, as they become more dominant through consolidation, prefer off-invoice trade promotions to performancebased promotions such as scan-backs. Gómez, Rao, and McLaughlin (2005) find that retailers with larger share of private label, larger annual sales, and stronger brand positioning do demand more trade promotion funds to off-invoices.
} 
Table 5: Difference in The Manufacturer's Profit between Multiple-Wholesale-Price Strategy \& Two-Wholesale-Price Strategy (\%)

\begin{tabular}{|c|c|c|c|c|c|c|c|c|c|c|c|c|c|c|c|}
\hline & \multicolumn{14}{|c|}{ holding cost h1 } \\
\hline & & 0.0005 & 0.005 & 0.01 & 0.02 & 0.03 & 0.04 & 0.05 & 0.06 & 0.07 & 0.08 & 0.09 & 0.1 & 0.11 & 0.12 \\
\hline \multirow{11}{*}{ b1 } & 1 & $0.00 \%$ & $0.00 \%$ & $0.00 \%$ & $0.00 \%$ & $0.00 \%$ & $0.00 \%$ & $0.00 \%$ & $0.00 \%$ & $0.00 \%$ & $0.00 \%$ & $0.00 \%$ & $0.00 \%$ & $0.00 \%$ & $0.00 \%$ \\
\hline & 1.05 & $0.03 \%$ & $0.05 \%$ & $0.04 \%$ & $0.00 \%$ & $0.00 \%$ & $0.00 \%$ & $0.00 \%$ & $0.00 \%$ & $0.00 \%$ & $0.00 \%$ & $0.00 \%$ & $0.00 \%$ & $0.00 \%$ & $0.00 \%$ \\
\hline & 1.1 & $0.07 \%$ & $0.14 \%$ & $0.13 \%$ & $0.10 \%$ & $0.00 \%$ & $0.00 \%$ & $0.00 \%$ & $0.00 \%$ & $0.00 \%$ & $0.00 \%$ & $0.00 \%$ & $0.00 \%$ & $0.00 \%$ & $0.00 \%$ \\
\hline & 1.15 & $0.11 \%$ & $0.25 \%$ & $0.24 \%$ & $0.22 \%$ & $0.00 \%$ & $0.00 \%$ & $0.00 \%$ & $0.00 \%$ & $0.00 \%$ & $0.00 \%$ & $0.00 \%$ & $0.00 \%$ & $0.00 \%$ & $0.00 \%$ \\
\hline & 1.2 & $0.15 \%$ & $0.34 \%$ & $0.35 \%$ & $0.26 \%$ & $0.34 \%$ & $0.00 \%$ & $0.00 \%$ & $0.00 \%$ & $0.00 \%$ & $0.00 \%$ & $0.00 \%$ & $0.00 \%$ & $0.00 \%$ & $0.00 \%$ \\
\hline & 1.25 & $0.19 \%$ & $0.42 \%$ & $0.47 \%$ & $0.39 \%$ & $0.47 \%$ & $0.13 \%$ & $0.00 \%$ & $0.00 \%$ & $0.00 \%$ & $0.00 \%$ & $0.00 \%$ & $0.00 \%$ & $0.00 \%$ & $0.00 \%$ \\
\hline & 1.3 & $0.22 \%$ & $0.50 \%$ & $0.55 \%$ & $0.51 \%$ & $0.52 \%$ & $0.26 \%$ & $0.00 \%$ & $0.00 \%$ & $0.00 \%$ & $0.00 \%$ & $0.00 \%$ & $0.00 \%$ & $0.00 \%$ & $0.00 \%$ \\
\hline & 1.35 & $0.25 \%$ & $0.57 \%$ & $0.63 \%$ & $0.58 \%$ & $0.58 \%$ & $0.32 \%$ & $0.04 \%$ & $0.00 \%$ & $0.00 \%$ & $0.00 \%$ & $0.00 \%$ & $0.00 \%$ & $0.00 \%$ & $0.00 \%$ \\
\hline & 1.4 & $0.27 \%$ & $0.62 \%$ & $0.69 \%$ & $0.62 \%$ & $0.55 \%$ & $0.31 \%$ & $0.08 \%$ & $0.00 \%$ & $0.00 \%$ & $0.00 \%$ & $0.00 \%$ & $0.00 \%$ & $0.00 \%$ & $0.00 \%$ \\
\hline & 1.45 & $0.29 \%$ & $0.66 \%$ & $0.72 \%$ & $0.64 \%$ & $0.48 \%$ & $0.26 \%$ & $0.07 \%$ & $0.00 \%$ & $0.00 \%$ & $0.00 \%$ & $0.00 \%$ & $0.00 \%$ & $0.00 \%$ & $0.00 \%$ \\
\hline & 1.5 & $0.31 \%$ & $0.68 \%$ & $0.73 \%$ & $0.64 \%$ & $0.37 \%$ & $0.18 \%$ & $0.03 \%$ & $0.00 \%$ & $0.00 \%$ & $0.00 \%$ & $0.00 \%$ & $0.00 \%$ & $0.00 \%$ & $0.00 \%$ \\
\hline
\end{tabular}

may indeed be optimal. Of course, such an explanation would be, admittedly, quite tenuous, given that our model does not offer a way to restrict the parameter space.

Second, we show that using only two price points allows the manufacturer to price discriminate between the dominant retailer and competitive fringe effectively and to capture the bulk of the benefits from trade promotions. When the manufacturer is "restricted" to adopt the two-wholesaleprice strategy only, all results under the multiple-wholesale-price strategy will hold! This means that this practice can also be justified based on the tradeoff between simplicity in administering trade promotions and profit gains. As Table 5 shows, the profit that the manufacturer sacrifices when switching from a regime of unconstrained multiple wholesale prices to a regime of constrained two wholesale prices is quite small (smaller than $1 \%$ ). This implies that even with the minimalist approach of two price points, the manufacturer can reap substantial benefits from trade promotions.

Finally, it is assumed that price changes are costless. In practice, cost of changing prices can be substantial, both in terms of monetary costs, and in terms of good will (Levy et al 1997). When such a cost is considered, the manufacturer may want to use two price points. 


\subsection{Finite Inventory Holding Costs for Both Retailers}

If the competitive fringe has a finite (as oppose to infinite in the basic model) unit inventory holding cost but such cost is still higher than the dominant retailer's, i.e., $0<h_{1}<h_{2}<\infty$, the manufacturer can still use trade promotions to price discriminate. The proofs are in Technical Appendix. The price discrimination comes about because of the extent to which different retailers can take advantage of trade promotions due to differences in holding costs.

\subsection{Generalizing from the Dominant Retailer Model}

Consider, for instance, an alternative demand model given by

$$
\begin{aligned}
& Q_{1}=a_{1}-b_{1} p_{1}+c_{1} p_{2} \\
& Q_{2}=a_{2}-b_{2} p_{2}+c_{2} p_{1}
\end{aligned}
$$

where $p_{i}$ is the price for retailer $i$ (Sayman et al 2002). In Technical Appendix TA, we show that in this model the manufacturer can price discriminate between retailers through trade promotions, even if both retailers independently and simultaneously make pricing decisions, as long as $\min \left\{b_{1}, b_{2}\right\}>\max \left\{c_{1}, c_{2}\right\}$. In other words, as long as the competing retailers exhibit different price sensitivities with regard to the wholesale price, and the higher price-sensitivity retailer has a lower inventory holding cost, the manufacturer can benefit from price discrimination through trade promotions.

\section{Conclusion and Discussion}

Many researchers have argued that trade promotions are harmful to manufacturers and to the distribution channel because of the added inventory-holding costs. Using a dominant retailer model, we show that trade promotions can benefit manufacturers and the channel precisely because of the added inventory cost: these costs provide the manufacturers with an opportunity to price discriminate between a dominant retailer and the competitive fringe. We show that the price 
discriminating function of trade promotions is not specific to the dominant retailer model and works for other competitive models also.

What this analysis implies is that manufacturers may want to proceed cautiously to "rein in" the practice of trade promotions. At the minimum, they need to weigh the benefit of pricediscrimination against any possible increase in the inventory and production costs in making such decisions.

The price discrimination perspective also sheds some new light on the practice of trade promotions. At a more general level, our analysis explains a few otherwise puzzling sets of practices associated with trade promotions: manufacturers do not seem to complain about the effectiveness of trade promotions or want to take the initiative of abandoning the practice (or when they do, they suffer); manufacturers allow forward buying but not diversion; power retailers urge for trade promotions but small and independent retailers frequently condemn the practice as unfair. Our analysis shows that price discrimination implemented through trade promotions could favor the manufacturer and the dominant retailer at the expense of the competitive fringe, and effective price discrimination can be implemented if there is forward buying but no diverting on the part of the dominant retailer.

Our analysis also shows that price discrimination induced through trade promotions can be welfare-enhancing as it alleviates the problem of double-marginalization in a distribution channel. We also show that trade promotions can increase social welfare, as the difference between retailers' holding costs is sufficiently large or the dominant retailer's market share is sufficiently small $\left(b_{1}\right.$ is large). Surprisingly, our analysis also finds that trade promotions may also benefit the competitive fringe under some conditions. The benefits to the competitive fringe come during promotional periods, in which all retailers enjoy the low wholesale price. Thus, when the dominant retailer has a high holding cost $h_{1}$ and a low market share (large $\left.b_{1}\right)$, the manufacturer will promote frequently with a high promotion depth to the benefit of the competitive fringe.

Our analysis suggests that one is more likely to observe trade promotions in industries or 
product categories where inventory holding cost is sufficiently small, or power retailers are not too dominant. These are testable predictions.

One could argue that trade promotions as a price discrimination mechanism are potentially more effective and robust than other pricing mechanisms such as quantity discounts or a menu of two part tariffs (Kuksov and Pazgal 2007). For instance, when a manufacturer uses quantity discounts to price discriminate against small retailers, the small retailers may be able to get together and pool their purchases to avail themselves of a low wholesale price. They can act similarly under a menu of two-part tariffs. However, with trade promotions, the competitive fringe retailers need to invest in joint warehouse facilities to be able to take advantage of periodic price deals. Said differently, as a price discrimination mechanism, trade promotions generate potentially less leakage than other posted price mechanisms.

While we believe that our analysis has generated some interesting new insights, it is important to point out the limitations of our model. In our model, we do not explicitly model product differentiation, although a downward sloping demand curve for the dominant retailer does suggest some differentiation in its offerings. If the retailers in the competitive fringe can offer vertically differentiated products to customers, we suspect that the competitive fringe will have more power and can be more profitable compared with the current model. ${ }^{20}$ We do not consider the manufacturer's holding costs in the model. If the manufacturer has to hold inventory instead of transferring all inventory to retailers and has lower inventory holding costs than retailers, will trade promotions still benefit the channel? We suspect that trade promotions can still be beneficial as the motivation for and the effects of, price discrimination in a channel do not go away because of a lower inventory holding cost on the part of the manufacturer. We also assume that the manufacturer is selling a single product through retailers. In multiple product setting, studies on how trade promotions on one product affect the profits of other products may generate additional insights (Chen and Xie 2007). Finally, we assume that the manufacturer is a monopoly in supplying products to retailers

\footnotetext{
${ }^{20}$ We thank an anonymous reviewer for pointing out this issue.
} 
(Liu and Zhang 2006). It is important for future research to investigate whether trade promotions could still help manufacturers to price discriminate between retailers in a competitive context. We suspect that they still could, as competition rarely negates any incentive for price discrimination. 


\section{References}

Accenture. 2001. The daunting dilemma of trade promotion: Why most companies continue to lose the battle - and how some are winning the war.

ACNielsen. 2004. Fourteenth annual survey of trade promotion practices.

Ailawadi, Kusum L., Paul Farris, Ervin Shames. 1999. Trade promotion: Essential to selling through resellers. Sloan Management Rev. 41(1) 83-92.

Agrawal, Deepak. 1996. Effect of brand loyalty on advertising and trade promotions: A game theoretic analysis with empirical evidence. Marketing Sci. 15(1) 86-108.

Blattberg, Robert C., Gary D. Eppen, Joshua Lieberman. 1981. A theoretical and empirical evaluation of price deals for consumer nondurables. J. Marketing 45(1) 116-129.

Bruce, Norris, Preyas S. Desai, Richard Staelin. 2005. The better they are, the more they give: Trade promotions of consumer durables. J. Marketing Res. 42(1) 54-66.

Buzzell, Robert D., John A. Quelch, Walter J. Salmon. 1990. The costly bargain of trade promotion. Harvard Bus. Rev. 68(2) 141-149.

Cannondale Associates. 2002,2003. Trade promotion spending \& merchandising industry study.

Chen, Yuxin, Jinhong Xie. 2007. Cross-market network effect with asymmetric customer loyalty: Implications for competitive advantage. Marketing Sci. 26(1) 52-66.

Drèze, Xavier, David R. Bell. 2003. Creating win-win trade promotions: Theory and empirical analysis of scan-back trade deals. Marketing Sci. 22(1) 16-39.

Dukes, Anthony J., Esther Gal-Or, Kannan Srinivasan. 2006. Channel bargaining with retailer asymmetry. J. Marketing Res. 43(1) 84-97.

Geylani, Tansev, Anthony J. Dukes, Kannan Srinivasan. 2005. Strategic manufacturer response to a dominant retailer. Marketing Sci. Forthcoming.

Gómez, Miguel I., Vithala R. Rao, Edward W. McLaughlin. 2005. Empirical analysis of budget and allocation of trade promotions in the US supermarket industry. Working Paper, Cornell University, Ithaca, New York.

Jeuland, Abel P., Chakravarthi Narasimhan. 1985. Dealing - temporary price cuts - by seller as a buyer discrimination mechanism. J. Bus. 58(3) 295-308.

Jeuland, Abel P., Steven M. Shugan. 1983. Managing channel profits. Marketing Sci. 2(3) 239-272. 
Jewell, William S. 1963. Markov-renewal programming. II: Infinite return models, example. Oper. Res. 11(6) 949-971.

Kahn, Barbara E., Leigh McAlister. 1997. Grocery Revolution, Addison-Wesley.

Kuksov, Dmitri, Amit Pazgal. 2007. The effects of costs and competition on slotting allowances. Marketing Sci. 26(2) 259-267.

Lal, Rajiv. 1990. Manufacturer trade deals and retail price promotions. J. Marketing Res. 27(4) 428-444.

Lal, Rajiv, John D. C. Little, J. Miguel Villas-Boas. 1996. A theory of forward buying, merchandising, and trade deals. Marketing Sci. 15(1) 21-37.

Levy, Daniel, Mark Bergen, Shantanu Dutta, Robert Venable. 1997. The magnitude of menu costs: Direct evidence from large U.S. supermarket chains. Quart. J. Econom. 112(3) 791825 .

Liu, Yunchuan, Z John Zhang. 2006. The benefits of personalized pricing in a channel. Marketing Sci. 25(1) 97-105.

Progressive Grocer. 2002. Standoff at the shelf: Big chains are happier with their treatment than small independents, but not that happy. 81(6).

Progressive Grocer Annual Report 1981, 2000, 2003.

Raju, Jagmohan S., Z. John Zhang. 2005. Channel coordination in the presence of a dominant retailer. Marketing Sci. 24(2) 254-262.

Samuelson, Paul A., William Nordhaus. 1989. Economics, New York: McGraw-Hill, 13th ed.

Sayman, Serdar, Stephen J. Hoch, Jagmohan S. Raju. 2002. Positioning of store brands. Marketing Sci. 21(4) 378-397.

Sellers, Patricia. 1992. The dumbest marketing ploy. Fortune, Oct 5th.

The McKinsey Quarterly. 2003. Value-driven shopping. Robert Frank, Elizabeth A. Mihas, and Laxman Narasimhan, Number 3.

U.S. Distribution Journal. 1992. Relations at the crossroads. December $17^{\text {th }}$.

U.S. Distribution Journal. 1993a. Quarter of wholesaler's income tied to trade promo funds: Study. April $15^{\text {th }}$.

U.S. Distribution Journal. 1993b. Wholesalers under the microscope: a study of the wholesale industry. May $15^{\text {th }}$.

Zwiebach, Elliot. 1990. Fair distribution sought for trade promo funds. Supermarket News. 


\section{Appendices}

\section{A. Retailers' Incentives To Reduce Holding Costs}

Assume $0<h_{1} \leq h_{2}<\infty$. The manufacturer will offer a wholesale price $w_{1}$ in the first period and $w_{i}$ in period $i$. Further, it will charge a $w_{1}$ and choose a pricing cycle length $N$ such that the competitive fringe will not make "bridge-buying", otherwise the manufacturer will offer a single wholesale price $w_{s}$, instead of offering a trade promotion with both retailers making bridge-buying. Intuitively, the dominant retailer, who is making "bridge buying", will have a larger incentive to reduce unit holding cost since the dominant retailer will reduce unit acquisition cost in each of the $N$ periods. The competitive fringe, who has a unit holding cost $h_{2}>h_{1}$ and is making "forward buying" for a shorter period than $\mathrm{N}$, will have a smaller incentive since it will benefit from reduced holding cost in less than $\mathrm{N}$ periods. We will formally prove this result below.

\section{Dominant retailer's incentives}

Given $w_{1}$ and $N$, the dominant retailer will choose a retail price $p^{i}=\frac{a+b_{1} w_{1}+b_{1} h_{1}(i-1)}{2 b_{1}}$ in period $i$ and its effective unit acquisition cost in period $i$ will be equal to $w_{1}+(i-1) h_{1},(i=1, \ldots, N)$. Therefore, the dominant retailer's profit in period $i$ is given by

$$
\pi_{d}^{i}=\left[p^{i}-w_{1}-(i-1) h_{1}\right]\left(a-b_{1} p^{i}\right)
$$

and its total profit in one pricing cycle is given by

$$
\pi_{d}^{T}=\sum_{i=1}^{N} \pi_{d}^{i}=\sum_{i=1}^{N}\left[p^{i}-w_{1}-(i-1) h_{1}\right]\left(a-b_{1} p^{i}\right)
$$

The dominant retailer's incentive to reduce holding cost $h_{1}$ is therefore given by ${ }^{21}$

$$
\frac{\partial \pi_{d}^{T}}{\partial h_{1}}=\sum_{i=1}^{N} \frac{\partial \pi_{d}^{i}}{\partial h_{1}}=-\sum_{i=1}^{N}(i-1)\left(a-b_{1} p^{i}\right)=-\sum_{i=1}^{N}(i-1) Q_{d i}<0
$$

That is, the dominant retailer's profit will be higher as its holding cost $h_{1}$ goes down.

\section{Competitive fringe's incentives}

We have stated that the retailers in the competitive fringe are not making bridge-buying as the dominant retailer is. Otherwise, trade promotions will not be profitable for the manufacturer. However, the competitive fringe's non-infinity unit holding cost $h_{2}$ makes it probable for the competitive fringe to make forward-buying in the promotional period. Let $\bar{x}$ be the number of periods in which the competitive fringe's effective unit acquisition cost in period $i=1, \ldots, \bar{x}$ is lower than the retail

\footnotetext{
${ }^{21}$ Here we use marginal analysis in studying retailers' incentives to reduce unit holding cost. That is, given $w_{1}, N$, and $\bar{x}$ (for competitive fringe), the dominant retailer's (any competitive fringe retailer's) incentive of reducing unit holding cost $h_{1}\left(h_{2}\right)$ is analyzed here.
} 
price $p^{i}$, if the competitive fringe makes forward-buying in the first period at the wholesale price $w_{1}$. That is, $w_{1}+(\bar{x}-1) h_{2} \leq p^{\bar{x}}$ and $w_{1}+(\bar{x}+1-1) h_{2}>p^{\bar{x}+1}$. Knowing the competitive fringe's effective acquisition cost, the manufacturer will not charge the retailers in competitive fringe a wholesale price equal to $p^{i}$ in periods 1 to $\bar{x}$, but charge them the effective unit acquisition cost $w_{1}+(i-1) h_{2}$ to make competitive fringe retailers indifferent between making forward-buying and ordering from the manufacturer in each period. Since the effective unit acquisition cost is not lower than the promotional price $w_{1}$, the manufacturer could have higher profits by charging them the effective acquisition cost than announcing a wholesale price equal to the retail price in period $i=1, \ldots, \bar{x}$. Assume $x$ makes the constraint equal

$$
w_{1}+(x-1) h_{2}=p^{x}=\frac{a+b_{1} w_{1}+b_{1} h_{1}(x-1)}{2 b_{1}},
$$

and we get $x=1+\frac{a-b_{1} w_{1}}{b_{1}\left(2 h_{2}-h_{1}\right)}$. Therefore we have,

$$
\begin{array}{r}
\bar{x}=\operatorname{int}[x]=\operatorname{int}\left[1+\frac{a-b_{1} w_{1}}{b_{1}\left(2 h_{2}-h_{1}\right)}\right] \text { and } \\
x-1<\bar{x} \leq x
\end{array}
$$

Assume there are $C$ identical retailers in the competitive fringe, each of whom has a demand proportion of $\frac{1}{C} Q_{c i}=\frac{1}{C}\left(b_{1}-b\right) p^{i}$ in period $i=1, \ldots, N$. Any retailer's effective unit acquisition cost of each item sold in period $i \leq \bar{x}$ equals $c_{2}^{i}=w_{1}+(i-1) h_{2}$, and the retailer's profit in period $i$ is given by

$$
\bar{\pi}_{c}^{i}=\left[p^{i}-w_{1}-(i-1) h_{2}\right] \times \frac{b_{1}-b}{C} p^{i}
$$

The retailer's profits from period $\bar{x}+1$ to period $N$ are zero because the manufacturer will take all surplus from the competitive fringe by charging a wholesale price slightly lower than the market price. So the total profit within a pricing cycle for any retailer in competitive fringe is given by

$$
\bar{\pi}_{c}^{T}=\sum_{i=1}^{\bar{x}} \bar{\pi}_{c}^{i}=\sum_{i=1}^{\bar{x}}\left[p^{i}-w_{1}-(i-1) h_{2}\right] \times \frac{b_{1}-b}{C} p^{i}
$$

The incentive for any retailer in the competitive fringe to reduce holding cost $h_{2}$ is given by

$$
\frac{\partial \bar{\pi}_{c}^{T}}{\partial h_{2}}=\sum_{i=1}^{\bar{x}} \frac{\partial \bar{\pi}_{c}^{i}}{\partial h_{2}}=-\sum_{i=1}^{\bar{x}}(i-1) \frac{b_{1}-b}{C} p^{i}=-\sum_{i=1}^{\bar{x}}(i-1) \frac{1}{C} Q_{c i}<0
$$

That is, the competitive fringe's profit will be higher as the holding cost $h_{2}$ goes down.

Since $\bar{x}<N$, equations (A.3) and (A.8) show that the dominant retailer has more incentives than any competitive fringe to reduce holding costs if the dominant retailer's demand $\left(Q_{d i}\right)$ is not smaller than the demand of any retailer in the competitive fringe $\left(\frac{1}{C} Q_{c i}\right)$ in periods $i=1, \ldots, \bar{x}$, or $\sum_{i=1}^{N}(i-1)\left(a-b_{1} p^{i}\right)>\sum_{i=1}^{\bar{x}}(i-1) \frac{b_{1}-b}{C} p^{i}$ for $Q_{d i} \geq \frac{Q_{c i}}{C}$.

Q.E.D. 
B. Proof of Lemma 1. Conditional on wholesale price $w_{s}$, the dominant retailer's profit in any period is given by,

$$
\pi_{d, s}=\left(p_{s}-w_{s}\right)\left(a-b_{1} p_{s}\right)
$$

The F.O.C. of the profit function determines the dominant retailer's optimal retail price, which is given by

$$
p_{s}=\frac{a+b_{1} w_{s}}{2 b_{1}}
$$

and retailers' demands are given by

$$
\left\{\begin{array}{l}
Q_{d, s}=a-b_{1} p_{s}=\frac{a-b_{1} w_{s}}{2} \\
Q_{c, s}=\left(b_{1}-b\right) p_{s}=\frac{\left(b_{1}-b\right)\left(a+b_{1} w_{s}\right)}{2 b_{1}}
\end{array} .\right.
$$

The manufacturer chooses $w_{s}$ to maximize its profit $\Pi_{s}=w_{s}\left(Q_{d, s}+Q_{c, s}\right)$. The optimal $w_{s}$ is given by

$$
w_{s}=\frac{a\left(2 b_{1}-b\right)}{2 b b_{1}}
$$

Given $w_{s}=\frac{a\left(2 b_{1}-b\right)}{2 b b_{1}}$, it is easy to derive other results in the lemma.

Q.E.D.

Proof of Lemma 2. The way to prove Lemma 2 is to consider the dominant retailer's decisions in an arbitrary period based on effective unit acquisition cost. The dominant retailer purchases inventory in the first period at a wholesale price $w_{1}$ and will be charged a unit holding cost $h_{1}>0$ per period for inventory it carries from one period to the next. Thus the effective unit acquisition cost of the units sold in period $j=1, \ldots, N$ is equal to $w_{1}+(j-1) h_{1}$. Here $w_{1}$ is the original purchase cost and $(i-1) h_{1}$ is the holding cost charged to each unit sold in period $i$. Therefore, the dominant retailer's profit for period $j$ is given by,

$$
\pi_{d, h_{1}}^{j}=\left[p^{j}-w_{1}-(j-1) h_{1}\right]\left(a-b_{1} p^{j}\right)
$$

and it will choose a retail price $p^{j}=\frac{a+b_{1} w_{1}+b_{1} h_{1}(j-1)}{2 b_{1}}$ in period $j$. Both the dominant retailer and the competitive fringe pay the promotional wholesale price $w_{1}$ in the first period. From the second period on, the manufacturer will charge the competitive fringe a wholesale price equal to the retail price to get all surplus from the competitive fringe since the competitive fringe takes the retail price $p^{j}$ as given in any period $j$. That is, $w_{j}=p^{j}$ for $j=2, \ldots, N$. The manufacturer's average profit per period in a pricing cycle is given below.

$$
\Pi_{h_{1}}=\frac{1}{N}\left[w_{1} \sum_{i=1}^{N}\left(a-b_{1} p^{i}\right)+w_{1}\left(b_{1}-b\right) p^{1}+\sum_{j=2}^{N} w_{j}\left(b_{1}-b\right) p^{j}\right],
$$

where $\sum_{i=1}^{N}\left(a-b_{1} p^{i}\right)$ is the dominant retailer's total ordering quantity, $p^{i}=\frac{a+b_{1} w_{1}+b_{1} h_{1}(i-1)}{2 b_{1}}$ is the retail price in period $i$, and $w_{j}=p^{j}$ is the wholesale price in period $j=2, \ldots, N$. Since $\Pi_{h_{1}}$ is strictly concave in $w_{1}$, F.O.C. solves $w_{1}$ as follows.

$$
w_{1}=\frac{N\left[4 a b_{1}-2 a b-b b_{1} h_{1}(N-1)\right]}{2 b_{1}\left[b(N+1)+b_{1}(N-1)\right]}
$$


Other results in Lemma 2 can then be easily derived.

Q.E.D.

Proof of Proposition 1. If $0 \leq h_{1}<h_{2}=\infty$, the manufacturer will offer wholesale prices $w_{1}$ and $w_{i}(i=2, . ., N)$ as in equation (3.1). For items sold in the promotional period, both the dominant retailer and competitive fringe are having same unit acquisition cost $w_{1}$. For items sold in period $i=2, \ldots, N$, the unit acquisition cost for the dominant retailer is equal to $w_{1}+h_{1}(i-1)$ and the cost for the competitive fringe is equal to the wholesale price in that period $w_{i}=\frac{a+b_{1} w_{1}+b_{1} h_{1}(i-1)}{2 b_{1}}$. We have $w_{i}-\left[w_{1}+h_{1}(i-1)\right]=\frac{a-b_{1}\left[w_{1}+h_{1}(i-1)\right]}{2 b_{1}}=\frac{a-b_{1} p^{i}}{b_{1}}>0$. Therefore, the competitive fringe is paying a higher average unit acquisition cost in a pricing cycle than the dominant retailer. If $0 \leq h_{1}<h_{2}<\infty$, the same logic still applies as long as the optimal pricing cycle length $N \geq 2$. The only difference is that it is possible that the retailers in the competitive fringe would also like to carry some inventory from one period to the next, but they will carry items for fewer periods than the dominant retailer because of their higher inventory holding cost. If they are carrying items for the same periods as the dominant retailer, trade promotions will not be worthy for the manufacturer and the optimal $N$ will be equal to 1, i.e., no trade promotions are offered. Q.E.D.

\section{Credibility of Manufacturer's Announcement of $\boldsymbol{N}$ and $w_{i}(i=1, \ldots, N)$}

In this section we will show that the manufacturer's announcement of both the length of pricing cycle $N$ and the wholesale price $w_{i}$ for each period $i$ within a pricing cycle consisting of $N$ periods $(i=1, \ldots, N)$ are credible. That is, given the announced $N$ and $w_{i}(i=1, \ldots, N)$ determined as in Lemma 2, the manufacturer will not have incentives to deviate from them. The intuition is as follows. Given the preannounced optimal $N$, the manufacturer will not have incentive to extend $N$ to any $\tilde{N}>N$. The reason for the manufacturer to run trade promotions is because trade promotions will provide a higher average profit per pricing cycle for the manufacturer than a time invariant wholesale price. If a manufacturer deviate from $N$ to $\tilde{N}>N$ and charge the optimal time invariant wholesale price $w_{s}$ as shown in Lemma 1 for periods $N+1, \ldots, \tilde{N}$ (the dominant retailer's inventory ordered in period 1 will be depleted in period $N$ ), the manufacturer will get a lower average profit per period for periods $N+1, \ldots, \tilde{N}$. Given the preannounced $N$, the manufacturer will have no incentive to deviate to any $\bar{N}<N$ either. In a pricing cycle, the manufacturer gets a much lower profit from units sold in period 1 than the average profit per period in the pricing cycle since the wholesale price $w_{1}$ is low and available to both the dominant retailer and competitive fringe. In each period $i(i=2, \ldots, N)$, however, the manufacturer will get a higher than average profit from units sold in the period. The higher than average profit comes from the manufacturer's complete gain of competitive fringe's surplus by charging a wholesale price equal to retail price in each period. If the manufacturer deviates to any $\bar{N}<N$, it will get a lower average profit per period for each pricing cycle since the manufacturer is cutting off the high profit periods $\bar{N}+1, \ldots, N$ while the dominant retailer will bring unsold units (due to the truncation of the pricing cycle) to 
the next pricing cycle. The manufacturer will thus have no incentive to either extend or shorten a pricing cycle from $N$ to any $\tilde{>} N$ or $\bar{N}<N$. In any period $i=2, \ldots, N$, the manufacturer will have no incentive to deviate from the preannounced $w_{i}$ either. Since $w_{i}=p^{i}$ for $i=2, \ldots, N$, the manufacturer will not increase the wholesale price since such an increase will let the manufacturer lose the profit from competitive fringe by making the wholesale price for the competitive fringe higher than the retail price. The manufacturer will also have no incentive to decrease wholesale price. If the reduced wholesale price in any period $i=2, \ldots, N$ (denoted as $\bar{w}_{i}$ ) is so low that the dominant retailer finds it profitable to make an order, it is equivalent to the case where the manufacturer starts a new pricing cycle (equivalently, chooses an $\bar{N}<N$ ), which is not optimal for the manufacturer as shown above. If the reduced wholesale price is not low enough to induce the dominant retailer to order in period $i=2, \ldots, N$, the manufacturer will lose a margin of $w_{i}-\bar{w}_{i}$ from competitive fringe, which is also not optimal. Either way, the manufacturer will not get a higher profit by deviate from the preannounced $w_{i}$. Thus, the manufacturer will not deviate from the preannounced $N$ and $w_{i}(i=1, \ldots, N)$.

Now we will proceed the proof in the following steps. First, we will show that the manufacturer will not have incentives to deviate from the optimal $N$. Second, we will show that the manufacturer will not have incentives to deviate from wholesale price $w_{i}$ for each period $i$ within a pricing cycle consisting of $N$ periods $(i=1, \ldots, N)$, given the dominant retailer's order in the first period $Q_{d}^{1}=\sum_{i=1}^{N} Q_{d i}=\frac{N}{4}\left[2\left(a-b_{1} w_{1}\right)-b_{1} h_{1}(N-1)\right]$.

\section{No Deviation from N}

Given both dominant retailer's and competitive fringe's decisions in Lemma 2, the manufacturer will not increase the length of pricing cycle from the optimal $N$ to any $\tilde{N}$ for $N<\tilde{N}<2 N^{22}$. Suppose the manufacturer changes the length of pricing cycle from $N$ to $\tilde{N}$ after the dominant retailer makes its order in the first period $Q_{d}^{1}=\frac{N}{4}\left[2\left(a-b_{1} w_{1}\right)-b_{1} h_{1}(N-1)\right]$. It is then optimal for the manufacturer to set a wholesale price at $w_{s}=\frac{a\left(2 b_{1}-b\right)}{2 b b_{1}}$ for each period $j(j=N+1, N+2, \ldots, \tilde{N})$ and gets an average profit per period of $\Pi_{s}=\frac{a^{2}\left(2 b_{1}-b\right)^{2}}{8 b b_{1}^{2}}$ for periods $N+1, N+2, \ldots, \tilde{N}$, if trade promotions are not used between periods $N+1$ and $\tilde{N}^{23}$. Since the reason for the manufacturer to provide trade promotions is because trade promotions will provide a higher average profit to the manufacturer than a common time-invariant wholesale price to retailers, it is not optimal for the manufacturer to deviate from $N$ to any $\tilde{N}>N$. Now lets show the manufacturer also has no incentives to shorten $N$ to any $\bar{N}<N$. In order to prove so, we need the following lemma, which shows that the manufacturer's profit from sales in period $N$ is the smallest among periods $2, \ldots, N$.

\footnotetext{
${ }^{22}$ If $\tilde{N} \geq 2 N$, then the focal periods we focus on will be from period $i_{N} \cdot N$ to period $\tilde{N}$ where $i_{N}=\operatorname{int}\left[\frac{\tilde{N}}{N}\right]$. We will then get similar insights as in the case where $N<\tilde{N}<2 N$.

${ }^{23} \mathrm{An}$ alternative way is for the manufacturer to use trade promotions to price discriminate between retailers between periods $N+1$ and $\tilde{N}$, but such a shorter pricing cycle will be suboptimal compared with the optimal pricing cycle with a length of $N$ since the optimal $N$ is determined such that it profit-dominates any other length of pricing cycle [please see Problem (3.3)].
} 
Lemma 3 In a pricing cycle, the manufacturer's profit from sales in a period is the minimum in period $j=\min \left\{N, \frac{b b_{1} w_{1}-\left(b_{1}-b\right)\left(a-b_{1} h_{1}\right)}{b_{1} h_{1}\left(b_{1}-b\right)}\right\}$ among periods $2, \ldots, N$.

Proof of Lemma 3. The sales in any period $j=2, \ldots, N$ consists of two parts - sales of the items the dominant retailer orders in period 1 at a wholesale price $w_{1}$ and carries to period $j$ and sales of the items the firms in competitive fringe order from the manufacturer at a wholesale price $w_{j}$ and sell in period $j$. The sales in period $j$ is equal to $Q_{j}=a-b p^{j}=\frac{2 a b_{1}-a b-b b_{1} w_{1}-b b_{1} h_{1}(j-1)}{2 b_{1}}$ as shown in Lemma 2. Manufacturer's profit from the sales in period $j=2, \ldots, N$ is thus given by

$$
\begin{aligned}
\Pi_{h_{1}}^{j} & =w_{1} Q_{d j}+w_{j} Q_{c j} \\
& =\frac{w_{1}\left[a-b_{1} w_{1}-b_{1} h_{1}(j-1)\right]}{2}+\frac{\left(b_{1}-b\right)\left[a+b_{1} w_{1}+b_{1} h_{1}(j-1)\right]^{2}}{4 b_{1}^{2}}
\end{aligned}
$$

The derivatives of $\Pi_{h_{1}}^{j}$ with respect to $j$ are given by

$$
\left\{\begin{array}{l}
\frac{d \Pi_{h_{1}}^{j}}{d j}=\frac{h_{1}\left[a\left(b_{1}-b\right)+b_{1} h_{1}\left(b_{1}-b\right)(N-1)-b b_{1} w_{1}\right]}{2 b_{1}} \\
\frac{d^{2} \Pi_{h_{1}}^{j}}{d j^{2}}=\frac{h_{1}^{2}\left(b_{1}-b\right)}{2}>0
\end{array}\right.
$$

Since the twice derivative of $\Pi_{h_{1}}^{j}$ with respect to $j$ is positive, $\Pi_{h_{1}}^{j}$ is strictly convex in $j$. Therefore, the manufacturer's profit $\Pi_{h_{1}}^{j}$ from sales is the minimum in period $j=\min \left\{N, \frac{b b_{1} w_{1}-\left(b_{1}-b\right)\left(a-b_{1} h_{1}\right)}{b_{1} h_{1}\left(b_{1}-b\right)}\right\}$ among periods $2, \ldots, N$, where $\frac{b b_{1} w_{1}-\left(b_{1}-b\right)\left(a-b_{1} h_{1}\right)}{b_{1} h_{1}\left(b_{1}-b\right)}$ is solved from the F.O.C. of $\Pi_{h_{1}}^{j}$. $\quad$ Q.E.D.

When the manufacturer offers trade promotions in period 1, the promotional wholesale price $w_{1}$ is same for both the dominant retailer and competitive fringe and $w_{1}$ is different from the optimal constant wholesale price $w_{s}$. Thus, the manufacturer's profit from sales in period 1 is smaller than the average profit under constant wholesale price $\Pi_{s}=\frac{a^{2}\left(2 b_{1}-b\right)^{2}}{8 b b_{1}^{2}}$. Since the reason for the manufacturer to offer trade promotions in the current model is because of a higher average profit in a pricing cycle than $\Pi_{s}$, the manufacturer's profit from items sold in period 1 is therefore smaller than the average profit in a pricing cycle. Starting from period 2, the manufacturer will have to get a higher profit from the items sold in each period than the average profit in order to "compensate" the profit "loss" in period 1. The higher than average profit in each period comes from sales to competitive fringe at a wholesale price of $w_{i}=p^{i}$. Such a "compensation" process continues until a period when the profit from that period is no longer contributable to improving the average profit per period in a pricing cycle, i.e. the average profit in that period is smaller than the average profit in a pricing cycle ${ }^{24} 25$. Thus the manufacturer will have no incentive to "cut"

\footnotetext{
${ }^{24}$ Numerical study shows that within the wide parametric ranges $\frac{d \Pi_{h_{1}}^{j}}{d j}$ is negative for $j=N$. That is, the manufacturer's average profit in each period among periods $2, \ldots, N$ is decreasing in $j$ for the studied parametric values.

${ }^{25}$ The manufacturer's profit from items sold in period $i$ by both retailers instead of its profit from items sold in period $i$ by competitive fringe only should be considered here. This is because if the manufacturer truncates a pricing cycle at period $i$ then the items that could have been sold by the dominant retailer in period $i$ will be carried over to the "new" pricing cycle in an infinitely repeated game.
} 
Table 6: Comparison of The Manufacturer's Profit in Period $\min \left\{N, \frac{b b_{1} w_{1}-\left(b_{1}-b\right)\left(a-b_{1} h_{1}\right)}{b_{1} h_{1}\left(b_{1}-b\right)}\right\}$ and Average Profit

\begin{tabular}{|c|c|c|c|c|c|c|c|c|c|c|c|c|c|c|c|}
\hline & & \multicolumn{14}{|c|}{ holding cost h1 } \\
\hline & & 0.0005 & 0.005 & 0.01 & 0.02 & 0.03 & 0.04 & 0.05 & 0.06 & 0.07 & 0.08 & 0.09 & 0.1 & 0.11 & 0.12 \\
\hline \multirow{11}{*}{ b1 } & 1 & $0.00 \%$ & $0.00 \%$ & $0.00 \%$ & $0.00 \%$ & $0.00 \%$ & $0.00 \%$ & $0.00 \%$ & $0.00 \%$ & $0.00 \%$ & $0.00 \%$ & $0.00 \%$ & $0.00 \%$ & $0.00 \%$ & $0.00 \%$ \\
\hline & 1.05 & $0.03 \%$ & $0.20 \%$ & $0.27 \%$ & $1.23 \%$ & $0.42 \%$ & $0.00 \%$ & $0.00 \%$ & $0.00 \%$ & $0.00 \%$ & $0.00 \%$ & $0.00 \%$ & $0.00 \%$ & $0.00 \%$ & $0.00 \%$ \\
\hline & 1.1 & $0.04 \%$ & $0.41 \%$ & $0.19 \%$ & $0.26 \%$ & $2.39 \%$ & $1.74 \%$ & $1.08 \%$ & $0.42 \%$ & $0.00 \%$ & $0.00 \%$ & $0.00 \%$ & $0.00 \%$ & $0.00 \%$ & $0.00 \%$ \\
\hline & 1.15 & $0.03 \%$ & $0.31 \%$ & $0.89 \%$ & $1.20 \%$ & $0.12 \%$ & $2.92 \%$ & $2.38 \%$ & $1.83 \%$ & $1.30 \%$ & $0.76 \%$ & $0.00 \%$ & $0.00 \%$ & $0.00 \%$ & $0.00 \%$ \\
\hline & 1.2 & $0.04 \%$ & $0.14 \%$ & $0.29 \%$ & $1.73 \%$ & $0.82 \%$ & $3.50 \%$ & $3.05 \%$ & $2.59 \%$ & $2.15 \%$ & $1.70 \%$ & $1.26 \%$ & $0.83 \%$ & $0.00 \%$ & $0.00 \%$ \\
\hline & 1.25 & $0.03 \%$ & $0.35 \%$ & $0.57 \%$ & $0.34 \%$ & $1.22 \%$ & $0.48 \%$ & $3.30 \%$ & $2.92 \%$ & $2.55 \%$ & $2.18 \%$ & $1.81 \%$ & $1.45 \%$ & $1.10 \%$ & $0.00 \%$ \\
\hline & 1.3 & $0.00 \%$ & $0.12 \%$ & $0.06 \%$ & $0.59 \%$ & $1.41 \%$ & $0.79 \%$ & $3.28 \%$ & $2.95 \%$ & $2.64 \%$ & $2.33 \%$ & $2.02 \%$ & $1.73 \%$ & $1.44 \%$ & $0.00 \%$ \\
\hline & 1.35 & $0.01 \%$ & $0.22 \%$ & $0.20 \%$ & $0.71 \%$ & $1.45 \%$ & $0.93 \%$ & $0.45 \%$ & $2.78 \%$ & $2.51 \%$ & $2.25 \%$ & $2.00 \%$ & $1.76 \%$ & $1.53 \%$ & $0.00 \%$ \\
\hline & 1.4 & $0.01 \%$ & $0.02 \%$ & $0.28 \%$ & $0.76 \%$ & $1.39 \%$ & $0.96 \%$ & $0.57 \%$ & $2.45 \%$ & $2.23 \%$ & $2.01 \%$ & $1.81 \%$ & $1.61 \%$ & $0.00 \%$ & $0.00 \%$ \\
\hline & 1.45 & $0.01 \%$ & $0.08 \%$ & $0.32 \%$ & $0.74 \%$ & $0.23 \%$ & $0.91 \%$ & $0.60 \%$ & $2.02 \%$ & $1.83 \%$ & $1.66 \%$ & $0.00 \%$ & $0.00 \%$ & $0.00 \%$ & $0.00 \%$ \\
\hline & 1.5 & $0.02 \%$ & $0.11 \%$ & $0.33 \%$ & $0.11 \%$ & $0.27 \%$ & $0.79 \%$ & $0.55 \%$ & $0.00 \%$ & $0.00 \%$ & $0.00 \%$ & $0.00 \%$ & $0.00 \%$ & $0.00 \%$ & $0.00 \%$ \\
\hline
\end{tabular}

at any period $i$ for $2<i<N$ since such a cutting will let the manufacturer lose the high margin in period $i$ associated with the order from competitive fringe and, at the same time, orders from the dominant retailer will not increase because any orders unsold due to the "cutting" will not be absorbed by the dominant retailer but be carried over to and sold in the new pricing cycle. This will generate a smaller average profit per period in a pricing cycle.

Table 6 shows numerical that the manufacturer's profit in period $\min \left\{N, \frac{b b_{1} w_{1}-\left(b_{1}-b\right)\left(a-b_{1} h_{1}\right)}{b_{1} h_{1}\left(b_{1}-b\right)}\right\}$ is always larger than its average profit per period in the pricing cycle when the manufacturer chooses to offer trade promotions to retailers. Therefore, the manufacturer has no incentive to truncate any pricing cycle into a pricing cycle with a length of $\bar{N}<N$ since the period $\min \left\{N, \frac{b b_{1} w_{1}-\left(b_{1}-b\right)\left(a-b_{1} h_{1}\right)}{b_{1} h_{1}\left(b_{1}-b\right)}\right\}$ with the lowest average profit among periods $2, \ldots, N$ has a higher than average profit. That is, the announcement of optimal $N$ is credible and self-enforcing - the manufacturer will not deviate to any $\tilde{N}>N$ or $\bar{N}<N$ in any period $i=2, \ldots, N$ within a pricing cycle.

\section{No Deviation from $w_{i}$}

In this subsection, we will show that the manufacturer will not deviate from pre-announced wholesale price $w_{i}$ in any period within a pricing cycle.

With the announced sequence of wholesale prices $w_{i}(i=1, \ldots, N)$, the manufacturer will charge the lowest wholesale price in period 1 in order to induce the dominant retailer to make forwardbuying. From period 2 until period $N$, the manufacturer will charge a wholesale price equal to retail price in each period in order to take full surplus from competitive fringe. In any period $i=2, \ldots, N$, the manufacturer will not increase the wholesale price $w_{i}$ to any larger price since such an increase will make the wholesale price higher than the retail price and thus the manufacturer will lose sales from competitive fringe. The margin with the dominant retailer, at the same time, 
does not improve because there is no sales to the dominant retailer in any period except in period 1 in a pricing cycle.

The manufacturer will also have no incentive to lower the wholesale price $w_{i}$ in any period $i=2, \ldots, N$. Suppose the manufacturer sets a wholesale price $\bar{w}_{i}<w_{i}$ in period $i$. One of the following two consequences will happen. In the first consequence, the new wholesale price is not low enough so the dominant retailer will keep selling inventory carried over from period 1, i.e. $\bar{w}_{i} \geq w_{1}+h_{1}(i-1)$. Such a decrease will then only decrease the manufacturer's profit since the margin the manufacturer gets from orders from competitive fringe is smaller while sales do not change at all. In the other consequence, the new wholesale price makes it more profitable for the dominant retailer to order from the manufacturer in period $i$, i.e. $\bar{w}_{i}<w_{1}+h_{1}(i-1)$. This is essentially same as the case where the manufacturer restarts a new pricing cycle. As shown above that it is not optimal for the manufacturer to deviate from the pre-announced $N$ to any $\bar{N}<N$, the manufacturer will not decrease wholesale price from $w_{i}$ to any $\bar{w}_{i}<w_{1}+h_{1}(i-1)$ in period $i=2, \ldots, N$.

Therefore, the manufacturer's announcements of both the length of pricing cycle $N$ and the sequence of wholesale prices $w_{i}, i=1, \ldots, N$, are credible and self-enforcing.

Q.E.D. 